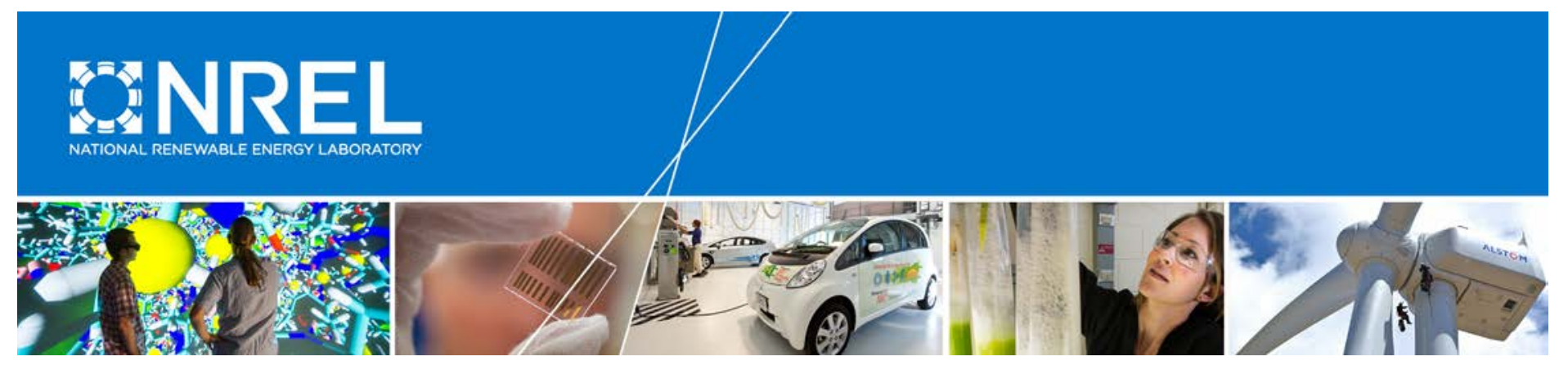

\title{
Methodology to Calculate the ACE and HPQ Metrics Used in the Wave Energy Prize
}

Frederick Driscoll, Jochem Weber, Scott Jenne, Robert Thresher, and Lee Jay Fingersh National Renewable Energy Laboratory

Diana Bull, Ann Dallman, Budi Gunawan, and Kelley Ruehl

Sandia National Laboratory

David Newborn and Miguel Quintero Naval Surface Warfare Center, Carderock Division

Alison LaBonte and Darshan Karwat U.S. Department of Energy

Scott Beatty

Cascadia Coast Research Ltd.

NREL is a national laboratory of the U.S. Department of Energy Office of Energy Efficiency \& Renewable Energy Operated by the Alliance for Sustainable Energy, LLC

This report is available at no cost from the National Renewable Energy Laboratory (NREL) at www.nrel.gov/publications.

Technical Report

NREL/TP-5000-70592

March 2018

Contract No. DE-AC36-08GO28308 


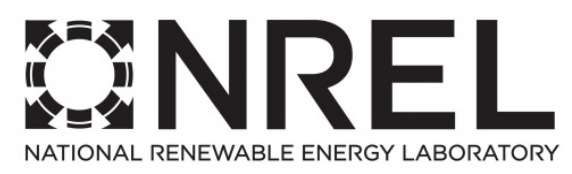

\section{Methodology to Calculate the ACE and HPQ Metrics Used in the Wave Energy Prize}

Frederick Driscoll, Jochem Weber, Scott Jenne, Robert Thresher, and Lee Jay Fingersh

National Renewable Energy Laboratory

Diana Bull, Ann Dallman, Budi Gunawan, and Kelley Ruehl

Sandia National Laboratory

David Newborn and Miguel Quintero Naval Surface Warfare Center, Carderock Division

Alison LaBonte and Darshan Karwat U.S. Department of Energy

Scott Beatty

Cascadia Coast Research Ltd.

\section{Suggested Citation}

Driscoll, Frederick, Jochem Weber, Scott Jenne, Robert Thresher, Lee Jay Fingersh, Diana Bull, Ann Dallman, Budi Gunawan, Kelley Ruehl, David Newborn, Miguel Quintero, Alison LaBonte, Darshan Karwat, Scott Beatty. 2018. Methodology to Calculate the ACE and HPQ Metrics Used in the Wave Energy Prize. Golden, CO: National Renewable Energy Laboratory. NREL/TP-5000-70592. https://www.nrel.gov/docs/fy18osti/70592.pdf.

NREL is a national laboratory of the U.S. Department of Energy Office of Energy Efficiency \& Renewable Energy Operated by the Alliance for Sustainable Energy, LLC

This report is available at no cost from the National Renewable Energy Laboratory (NREL) at www.nrel.gov/publications.

\section{Technical Report}

NREL/TP-5000-70592

March 2018

Contract No. DE-AC36-08G028308
National Renewable Energy Laboratory 15013 Denver West Parkway Golden, CO 80401

303-275-3000 • www.nrel.gov 


\section{NOTICE}

This report was prepared as an account of work sponsored by an agency of the United States government. Neither the United States government nor any agency thereof, nor any of their employees, makes any warranty, express or implied, or assumes any legal liability or responsibility for the accuracy, completeness, or usefulness of any information, apparatus, product, or process disclosed, or represents that its use would not infringe privately owned rights. Reference herein to any specific commercial product, process, or service by trade name, trademark, manufacturer, or otherwise does not necessarily constitute or imply its endorsement, recommendation, or favoring by the United States government or any agency thereof. The views and opinions of authors expressed herein do not necessarily state or reflect those of the United States government or any agency thereof.

This report is available at no cost from the National Renewable Energy Laboratory (NREL) at www.nrel.gov/publications.

Available electronically at SciTech Connect http:/www.osti.gov/scitech

Available for a processing fee to U.S. Department of Energy and its contractors, in paper, from:

U.S. Department of Energy

Office of Scientific and Technical Information

P.O. Box 62

Oak Ridge, TN 37831-0062

OSTI http://www.osti.gov

Phone: 865.576.8401

Fax: 865.576.5728

Email: reports@osti.gov

Available for sale to the public, in paper, from:

U.S. Department of Commerce

National Technical Information Service

5301 Shawnee Road

Alexandria, VA 22312

NTIS http://www.ntis.gov

Phone: 800.553 .6847 or 703.605 .6000

Fax: 703.605.6900

Email: orders@ntis.gov 


\section{Acknowledgements}

The authors graciously acknowledge the support of the U.S. Department of Energy and the Office of Naval Research for their support of the Wave Energy Prize. The authors also thank the many people at the Prize Administration Team, U.S. Department of Energy and Department of Defense national laboratories, and university test facilities who worked long hours, evenings, and weekends to make the prize a success. Finally, we want to acknowledge the outstanding effort of the teams, many of whom proceeded from a concept on paper to a 1:20 scale working prototype. 


\section{List of Acronyms}

$A C C W$

$A C E$

$C C E$

$C W$

DOE

$H P Q$

IWS

JONSWAP

LCOE

MASK

$M M C$

PTO

RM3

$R S T$

TPL

TRL

WEC average climate capture width

$\mathrm{ACCW} / C C E$

characteristic capital expenditure

capture width

U.S. Department of Energy

hydrodynamic performance quality

irregular wave state

Joint North Sea Wave Project

levelized cost of energy

Naval Surface Warfare Center - Carderock Division's Maneuvering and Seakeeping Basin

manufactured material cost

power take-off

Reference Model \#3

representative structural thickness

technology performance level

technology readiness level

wave energy converter 


\section{Abstract}

The U.S. Department of Energy's Wave Energy Prize Competition encouraged the development of innovative deep-water wave energy conversion technologies that at least doubled device performance above the 2014 state of the art, based on U.S. reference models. Because levelized cost of energy (LCOE) metrics are challenging to equitably apply to new technologies where significant uncertainty exists in design and operation, the prize technical team developed a reduced metric as proxy for LCOE, which provides an equitable comparison of low technology readiness level wave energy converter (WEC) concepts.

The metric is called " $A C E$ " which is short for the ratio of the Average climate capture width to the Characteristic capital Expenditure. ${ }^{1} A C E$ can be thought of as the equivalent wave crest width, for which the wave energy converter can absorb all incoming wave energy, that can be built per million dollars spent on load bearing structure. The value of $A C E$ for 2014 state-of-theart deep-water WEC technologies was estimated at $1.5 \mathrm{~m} / \$ \mathrm{M}$ for deployment on the West Coast of the United States, yielding a prize threshold of $3.0 \mathrm{~m} / \$ \mathrm{M}$ when doubled. To account for additional important characteristics that affect the LCOE, the resulting $A C E$ value is multiplied by a performance-based scale factor called hydrodynamic performance quality, determined from other data collected during testing.

Each of the prize finalists tested technologies at the Naval Surface Warfare Center, Carderock Divisions' Maneuvering and Sea Keeping test facility to provide measured performance and other data. Finalists were provided separate one-week access to the testing basin where their devices were subject to 10 different sea states. These sea states were selected to be representative of operating and energetic conditions on the West Coast of the United States.

The methodology and application of the $A C E$ metric used to evaluate the performance of the technologies that competed in the Wave Energy Prize are explained herein. First, an overview of the prize is presented with details on the development of the $A C E$ metric. Next, the average climate capture width calculation is described. Finally, the methodology used to calculate the characteristic capital expenditure is described.

\footnotetext{
${ }^{1} \mathrm{ACCW}$ is the absorbed power of the device divided by the wave energy flux per meter crest width, and $C C E$ is a first-order estimate of the structural cost. A value for the $C C E$ was calculated for each team based on its technical submissions, and ACCW was calculated from 1:20 scale test results.
} 


\section{Table of Contents}

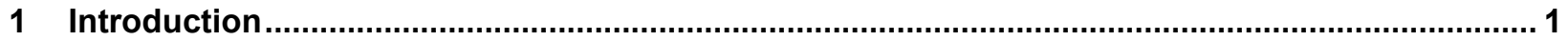

2 Overview of the ACE and Hydrodynamic Performance Quality Metrics....................................... 4

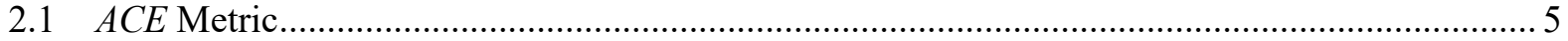

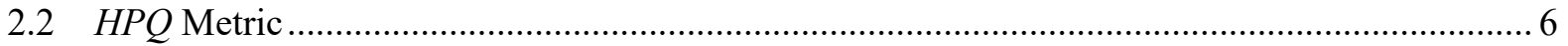

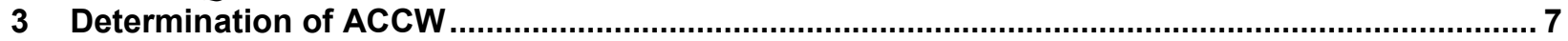

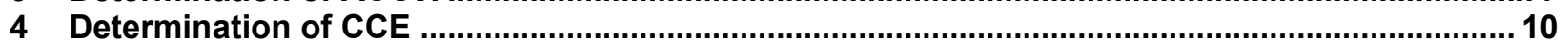

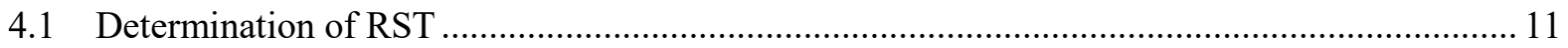

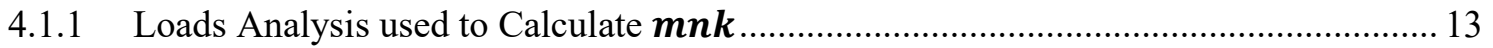

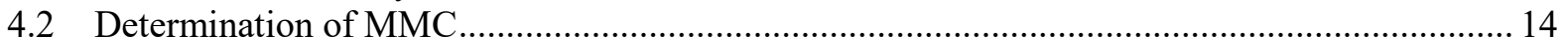

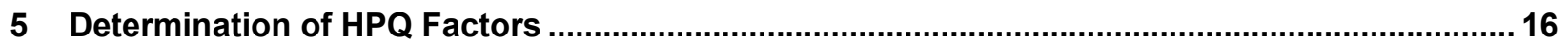

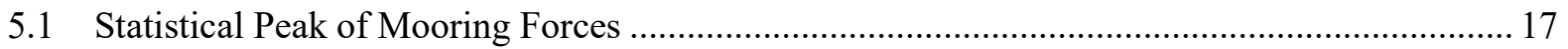

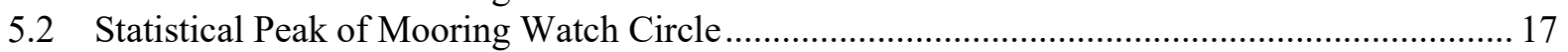

5.3 Statistical Peak-to-Average Ratio of Absorbed Power ........................................................... 18

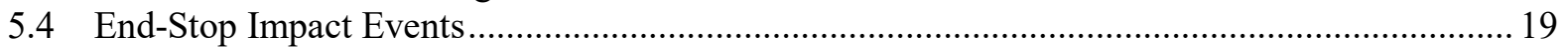

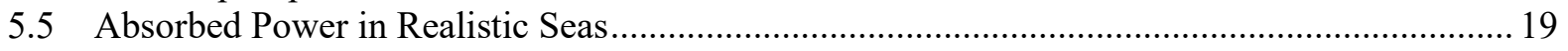

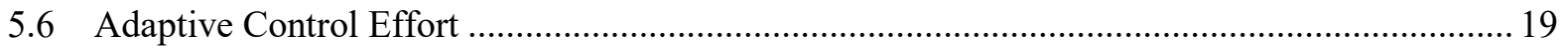

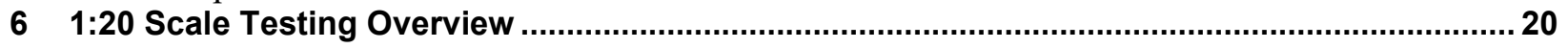

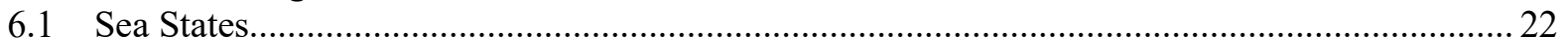

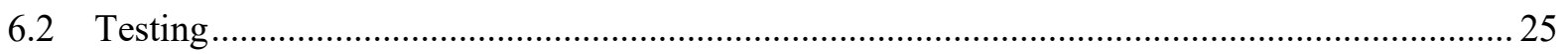

6.3 Data Acquisition, Sensors, Data Quality Assurance ........................................................ 27

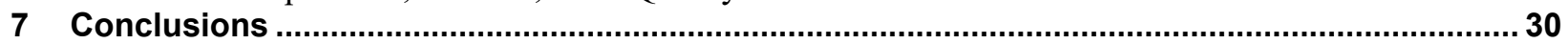

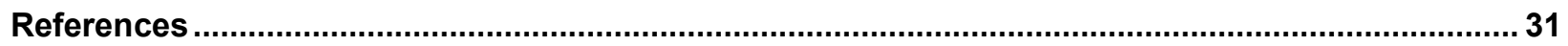

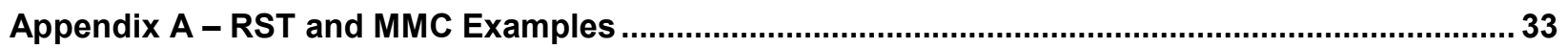

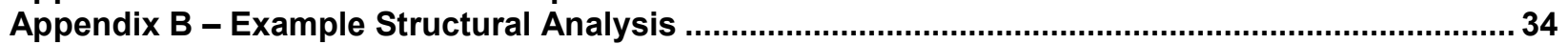

Appendix C - Wave Repeatability and Spatial Variability Analysis................................................ 36

\section{List of Figures}

Figure 1. Schedule of the Wave Energy Prize with the various activities separated into the three phases .. 3 Figure 2. Schematic showing the flow of data in the $A C E$ and $H P Q$ calculations. Light blue boxes indicate data sources and dark blue boxes indicate calculations ........................................................ 5

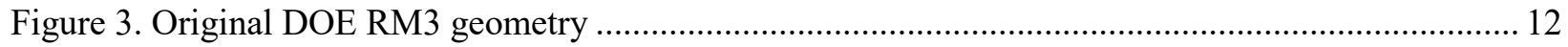

Figure 4. Simplified DOE Reference Model geometry ................................................................. 12

Figure 5. Visual representation of the $R S T$ concept for a component originally composed of plate and beams. All the material from the plate and beam structure (left) are distributed equally as a simple plate over the simplified surface area (right).......................................................... 13

Figure 6. General schematic of bridge and MASK basin; note: this drawing shows a previous version to

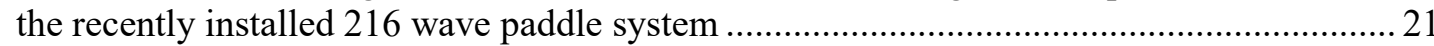

Figure 7. MASK basin with arrows depicting the direction of wave propagation.................................... 22

Figure 8. Wave spectra for the IWS 1 for the three 25-minute window data sets with start times staggered

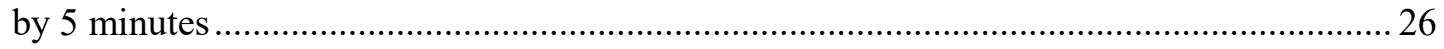

Figure 9. Wave spectra for the LIWS 2 for the three 25-minute window data sets with start times

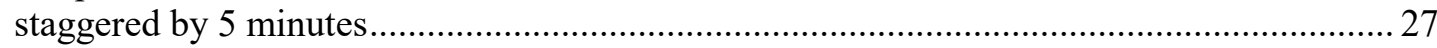

Figure 10. Wave spectra for the RWS 1 for the three 25-minute window data sets with start times

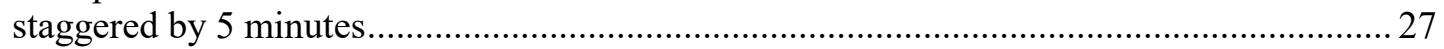

Figure 11. Schematic showing the data flow from the sensors through the data acquisition system (DAS) and to the processing and quality assurance that was provided between tests........................2 29

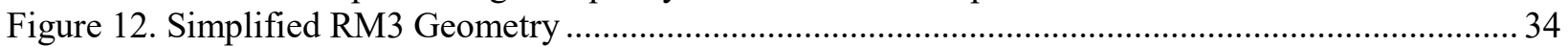

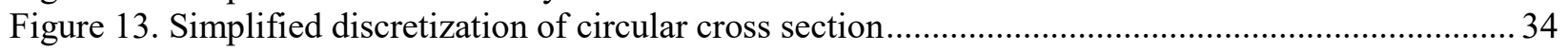

vii 
Figure 14. Time series of the same IWS 1 wave for four different teams (left figure) and spectra of the same IWS 1 wave for four different teams (right figure)................................................. 36

Figure 15. Time series of the same IWS 3 wave for four different teams (left figure) and spectra of the same IWS 3 wave for four different teams (right figure)..................................................... 36

Figure 16. Time series of the same LIWS 1 wave for four different teams (left figure) and spectra of the same LIWS 1 wave for four different teams (right figure) .................................................. 37

Figure 17. Time series of the same RWS 1 wave for four different teams (left figure) and spectra of the same RWS 1 wave for four different teams (right figure)

Figure 18. Spectra for all 12 calibration wave probes for IWS 1 (left) and the average spectra for all 12 calibration wave probes and the specified JONSWAP for IWS 1 (right) ............................. 38

Figure 19. Spectra for all 12 calibration wave probes for IWS 3 (left) and the average spectra for all 12 calibration wave probes and the specified JONSWAP for IWS 3 (right) ............................. 38

Figure 20. Spectra for all 12 calibration wave probes for LIWS 2 (left) and the average spectra for all 12 calibration wave probes and the specified JONSWAP for LIWS 2 (right)............................ 38

Figure 21. Spectra for all 12 calibration wave probes for RWS 1 (left) and the average spectra for all 12 calibration wave probes and the specified JONSWAP for RWS 1 (right) .............................. 39

\section{List of Tables}

Table 1. Full-Scale Properties of the Unidirectional Sea States used to Calculate $A C C W$.

Table 2. Scaling Factors Used to Calculate the Net $A C C W$ and the Full-Scale Average Annual Wave

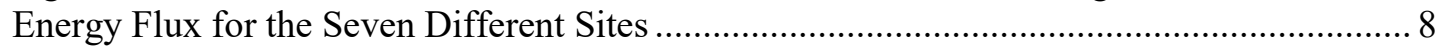

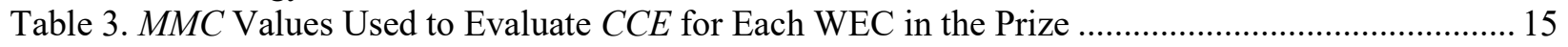

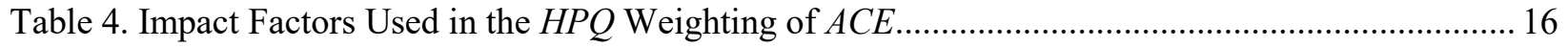

Table 5. Full-Scale Properties of the Additional Four Sea States Used to Calculate the $H P Q$................. 17

Table 6. Parameters for the 10 1:20 Scale Sea States. Direction is Specified Relative to the Forward-

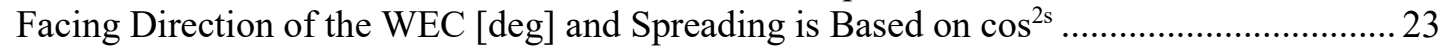

Table 7. Average and Standard Deviation between the 12 Wave Probes for the Wave Height, Energy

Flux, and Energy Period within the Test Area for all 10 Test Sea States Measured

Underneath the Carriage at the WEC Deployment Location................................................. 24

Table 8. Breakdown and Duration of Each Wave Test......................................................................... 25

Table 9. Average and Standard Deviation of the Wave Height, Energy Flux and Energy Period of the Three 25-Minute Window Data Sets with Start Times Staggered by 5 Minutes within the Test Area for all 10 Test Waves Calculated...... 


\section{Introduction}

Ocean wave energy converter (WEC) technologies include many archetypes that span the range of technology readiness levels (TRLs). Initially developed by the National Aeronautics and Space Administration, the U.S. Department of Energy (DOE) has developed guidance for using the TRLs within energy research [1]. Novel concepts and technical innovations continue to drive research and development aimed at increasing wave energy capture efficiency and reducing costs as evidenced by a sustained growth in patent activity. However, funding is difficult to secure for performance testing and evaluation of WEC devices in wave tanks at a meaningful scale. This is a problem for the industry because scaled WEC prototype tank testing, validation, and evaluation are key steps in the advancement of WEC technologies through the TRLs and the technology performance levels (TPLs) to reach commercialization and economic performance, respectively. The TPL is a complementary metric that is used to predict the economic competitiveness of a technology [2].

To address the research and development challenges and barriers experienced by many new and innovative technologies, the DOE's Wave Energy Prize Competition was launched in 2014. The competition encouraged development of innovative deep-water wave energy technologies that would at least double device performance above the 2014 state of the art. The competition attracted 92 teams with a goal of involving new entrants to the field while motivating and inspiring existing WEC technology developers.

The competition comprised three phases and four technology gates where each team's technologies were progressively tested and evaluated [3]. At each technology gate, the teams were ranked against established criteria and the teams that best meet those criteria are selected to move to the next phase of the competition. A diagram of the technology gates with key actions and dates is shown in Figure 1. The competition's phases and gates were arranged as follows:

- Phase I, Design. The design phase started the competition on April 1, 2016. The WEC concepts were evaluated using the TPL methodology. Sixty-six teams entered technical submissions, and 20 teams qualified to proceed to Phase II at Technology Gate 1.

- Phase II, Build. Each team used numerical simulations to estimate its WEC's performance. The teams then developed 1:50 scale physical prototypes that were tested at various smaller wave tank facilities. The nine teams and two alternates that had the best combination of 1) agreement between model results and test results, 2) energy capture, 3) re-evaluation of TPL, and 4) prediction of $A C E^{2}$ expected in the Naval Surface Warfare Center, Carderock Division's Maneuvering and Seakeeping (MASK) Basin were selected at Technology Gate 2 to build 1:20 scale WEC models. Towards the end of Phase II, each team's build progress was reviewed, and their readiness for wave testing was verified at Technology Gate 3. All nine finalist teams were qualified for testing at the MASK basin

${ }^{2} \mathrm{ACE}$ is the ratio of the average climate capture width (ACCW) to the characteristic capital expenditure (CCE). $\mathrm{ACCW}$ is the absorbed power of the device divided by the wave energy flux per meter crest width, and CCE is a first-order estimate of the structural cost. These are further described in Section 2.1. 
- Phase III, Testing and Evaluation. Each of the nine finalist teams participated in a oneweek intensive test at the MASK basin where its WEC model was subject to a set of 10 test sea states. Measurements from the MASK tests and estimates of capital costs were used to determine the winners.

An incremental testing approach was adopted, starting at small-scale testing (1:50 scale), then moving to larger scale $(1: 20)$. Many teams entered the prize with an early stage concept and did not have physical evidence to back up their claims in their technical submissions. The first test, at 1:50 scale, was performed early on during the competition period to evaluate the teams' claims against the measured response. This first round of testing also required the teams to build physical and numerical models, which were another check used to verify a team's capability to succeed at subsequent stages. To prepare the Wave Energy Prize teams for the 1:20 scale testing at MASK, a dry run test was performed using a representative instrumented physical model. All test sea states were run, and data analysis and quality assurance were performed to verify prize readiness for team tests and to identify deficiencies with sufficient time for them to be corrected. The 1:20 test provided quantitative data on WEC performance that were used to determine the prize metrics.

The first stage of the competition had nine judges to review and down select entries through a TPL assessment to the 20 teams that proceeded to the second stage of the competition. In the remaining stages, five judges reviewed all test results and documents. 

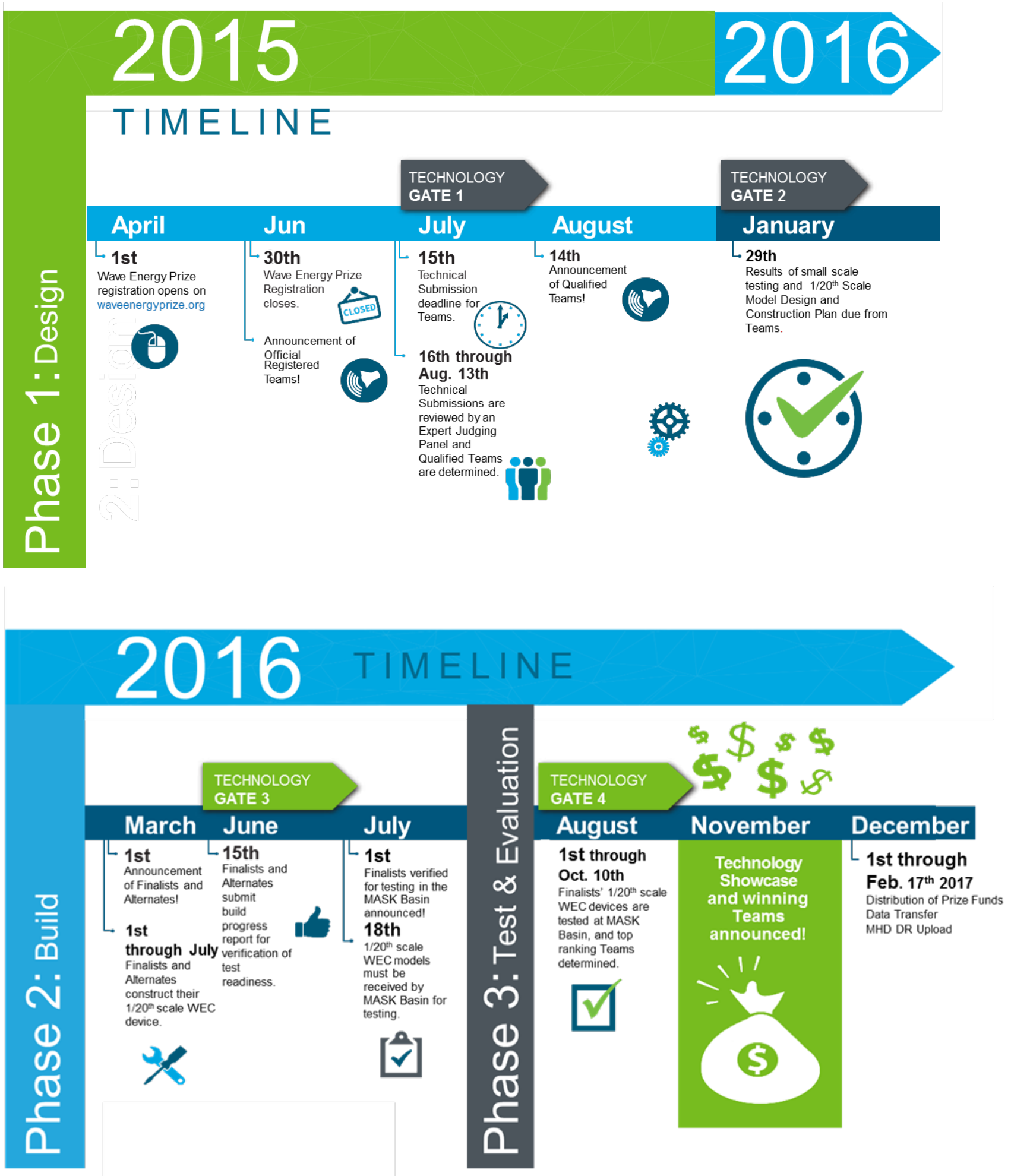

Figure 1. Schedule of the Wave Energy Prize with the various activities separated into the three phases 


\section{Overview of the ACE and Hydrodynamic Performance Quality Metrics}

The levelized cost of energy (LCOE) metric is used to evaluate the economic potential by integrating both cost and performance of energy technologies. Levelized cost of energy (LCOE) is defined as the net present value cost of planning, constructing, operating, and decommissioning a generating plant divided by the total electricity generated over the assumed financial life of the asset. LCOE is expressed in dollars per megawatt-hour ( $\$ \mathrm{MWh})$. This metric can be used to evaluate single devices as well as arrays consisting of multiple devices [4].

However, an accurate LCOE estimate requires detailed information on capital costs, e.g., infrastructure, mooring systems, installation costs, and operations and maintenance costs (e.g., marine and shoreside operations and maintenance, environmental monitoring, and insurance). This type of detailed information is not typically available for low TRL technologies. In addition, it is problematic to use LCOE estimates to compare different technologies at disparate TRLs when significant uncertainties exist in materials, design and operation.

As a result, a variety of reduced metrics serving as proxies to LCOE have been proposed to evaluate and compare different WEC technologies [5, 6, 7]. The $A C E$ is a reduced metric, specifically designed for the Wave Energy Prize, to provide an equitable comparison of low-TRL WEC concepts. $A C E$ can be thought of as the equivalent wave crest width, for which the wave energy converter can absorb all incoming wave energy, that can be built per million dollars spent on load bearing structure. The value of $A C E$ for state-of-the-art deep-water WEC technologies (in 2014, based on the DOE reference model project $[6,8]$ ) was estimated at 1.5 meters per million dollars $(\mathrm{m} / \mathrm{\$ M})$ for deployment in a representative West Coast wave climate of the United States, yielding a prize threshold of $3.0 \mathrm{~m} / \$ \mathrm{M}$ as a necessary requirement to win the prize. To account for other key aspects that affect the LCOE but are not captured by the $A C E$ metric, another factor called hydrodynamic performance quality $(H P Q)$ was developed. $H P Q$ is a scale factor with components that can either increase or decrease the $A C E$ value based on mooring forces, marine space usage, smoothness of power delivery, mechanical impact forces, ability to absorb power in less than ideal conditions, and complexity of the WEC's control system.

Finalists that met or exceeded the $A C E$ threshold were ranked based on their $H P Q$ score. The $A C E$ and $H P Q$ metrics comprise several other metrics and use data from team technical submissions and from the 1:20 scale testing. A schematic showing how test and other data contribute to the $A C E$ and $H P Q$ metrics is shown in Figure 2. Each section and subsection of this document define the contributors to the $A C E$ and $H P Q$ metrics observed in Figure 2. Data are collected from a team's technical submission and from the 1:20 scale testing. Those data are then used to calculate the various components of $A C E$ and $H P Q$. 


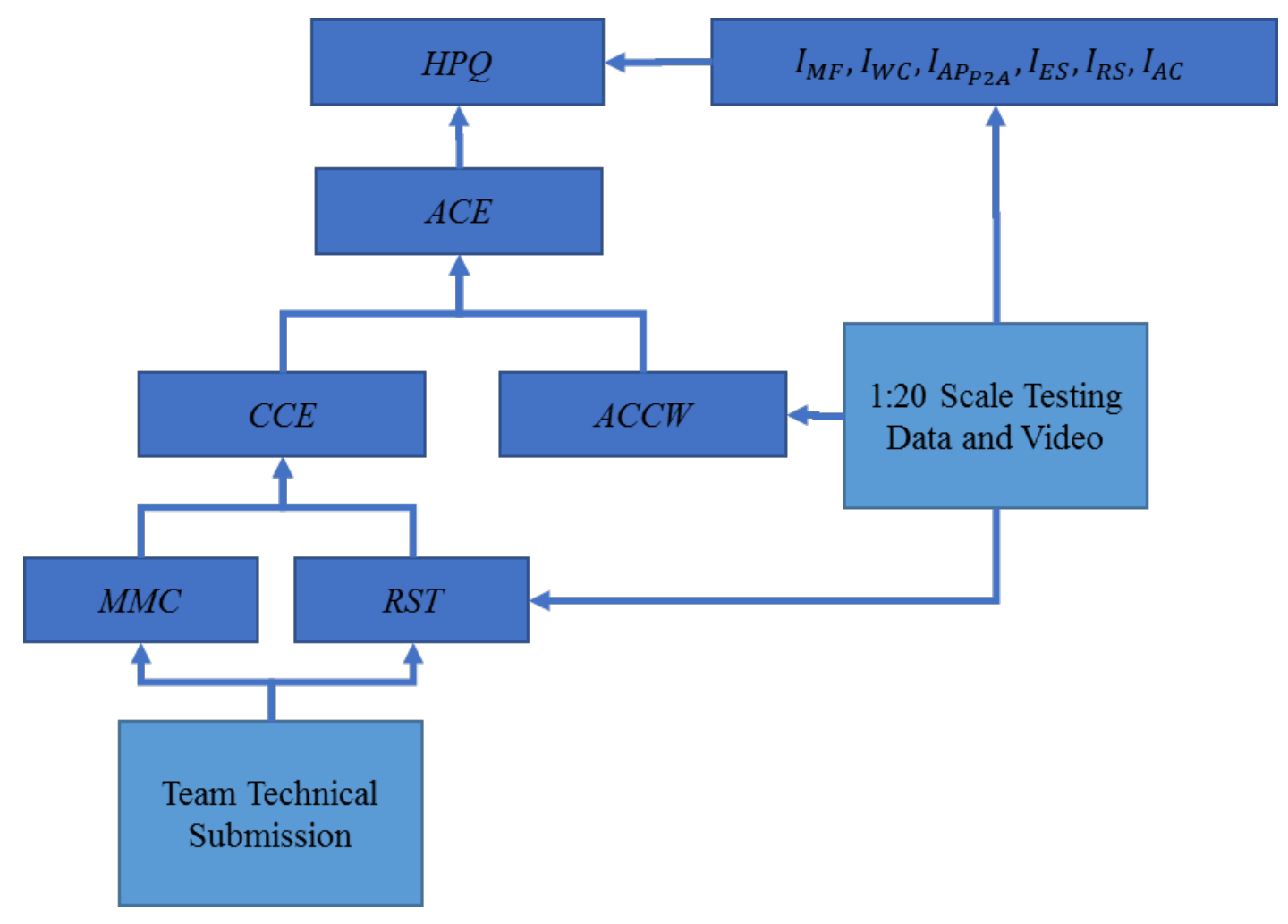

Figure 2. Schematic showing the flow of data in the $A C E$ and $H P Q$ calculations. Light blue boxes indicate data sources and dark blue boxes indicate calculations

\subsection{ACE Metric}

The $A C E$ metric is determined from the ratio of two components, the average climate capture width $(\overline{A C C W})$ to the characteristic capital expenditure $(C C E)[3]$ :

$$
A C E=\frac{\overline{A C C W}}{C C E}
$$

Capture width $(C W)$ is a common metric used in evaluating WEC technology energy capture performance [9]. $C W$ is defined as the ratio of absorbed wave power (in kilowatts) to the energy in the wave resource (in kilowatts per meter) [9]. Because $C W$ will vary from wave to wave, an average $C W$ for the area for which a WEC is deployed, $\overline{A C C W}$, defined in Section 3, is used in the prize competition. The $\overline{A C C W}$ is a normalized scalar measure of the weighted average of a WEC's energy capture from several representative sea states at many different sites. In the prize competition, the $\overline{A C C W}$ represents a composite value of a WEC's energy capture for the Pacific Coast Region of the United States. Values for the wave power absorbed by the WEC technologies were measured using 1:20 scale physical models that were tested at MASK and scaled to full size using Froude scaling [10].

For the early-stage technologies within the prize, specific details on the conversion chain from mechanical to electric power are typically unknown, and the losses are un-characterized. In addition, accurate physical modeling of an electric generator at 1:20 scale is expensive and can introduce experimental issues. Therefore, for the prize, the power is measured at the closest 
location within the power take-off (PTO) to where the power is first converted from the wave energy flux to mechanical power. ${ }^{3}$ The power at this stage of the conversion chain is referred to as absorbed power. Consequently, the $A C C W$ and $A C E$ neglect power conversion losses in the PTO but facilitate the necessary comparisons of the WECs.

Both domestic and international efforts to capture WEC cost drivers consistently demonstrate that structural costs are by far the largest contributor to overall LCOE $[8,11,12]$. Typical WEC structures account for approximately $37 \%-52 \%$ of the overall LCOE [13]. While accurate project costing is typically not available at lower TRLs, reasonable estimates of structural costs can be obtained through first-order structural modelling and application of material and fabrication costs specified by unit of material weight. More detail on the methodology to calculate the $C C E$ is defined in Section 4.

\subsection{HPQ Metric}

The $H P Q$ metric is applied to account for device performance characteristics not included in $A C E$, but that would typically affect an LCOE calculation and that can be inferred by measurements and observations from the MASK testing. HPQ can also identify and provide consideration of issues associated device feasibility that may manifest during testing. $H P Q$ can be visualized as the $A C E$ score weighted by the device performance during testing in six areas. $H P Q$ is defined as:

$$
H P Q=A C E \cdot\left[I_{M F} \cdot I_{W C} \cdot I_{A P P 2 A} \cdot I_{E S} \cdot I_{R S} \cdot I_{A C}\right]
$$

where the performance impact factors are defined as follows:

- $I_{M F}$, based on the statistical peak of the mooring force, accounting for mooring loads intensity

- $\quad I_{W C}$, the statistical peak of the mooring watch circle, accounting for station keeping ability

- $\quad I_{A P_{P 2 A}}$, the ratio of statistical peak-to-average of absorbed power, accounting for variability of the absorbed power

- $\quad I_{E S}$, the number of end-stop impact events, accounting for frequency and severity of mechanical end-stop impacts

- $I_{R S}$, the absorbed power in realistic seas

- $I_{A C}$, accounting for the adaptive control effort.

All factors except $I_{A C}$ used data calculated from measurements and event counts from the MASK testing. The values used for $I_{A C}$ were based on the observed complexity of the controller used. See Section 5 for details on the determination of the impact factors.

\footnotetext{
${ }^{3}$ Numerical- and computer-based model power estimates can be substituted for test measurements when calculating the ACCW, but power values must be estimated at the closest point within the PTO where wave energy flux is converted to mechanical power.
} 


\section{Determination of ACCW}

For a set of sea states at a geographic location $j$, the $A C C W$ is defined as the weighted average of the absorbed power of a WEC for $i$ different sea states divided by the incident wave energy flux per meter crest width:

$$
A C C W_{j}=\frac{\sum_{i=1}^{n} \Xi_{i j}\langle A P(i)\rangle}{\left\langle C_{P}(j)\right\rangle}
$$

where:

- $n$ is the number of sea states

- $\quad \Xi_{i j}$ is the scaling factor for sea state $i$ at each location $j$

- $\langle A P(i)\rangle$ is the average power absorbed by the WEC for sea state $i$ measured at the closest point in the PTO where wave energy flux is first converted to mechanical power

- $\left\langle C_{P}(j)\right\rangle$ is the incident average annual wave energy flux for site $j$ [14].

In the prize, $A C C W$ is calculated for $(n=6)$ six unidirectional long-crested sea states that occur off the west coast of the United States, including Alaska and Hawaii. The full-scale sea state parameters are summarized in Table 1, and the selection methodology can be found in [14].

Table 1. Full-Scale Properties of the Unidirectional Sea States used to Calculate ACCW

\begin{tabular}{lllll}
\hline Wave Designation & $\begin{array}{l}\text { Wave Ref } \\
\text { Number, } \boldsymbol{i}\end{array}$ & $\begin{array}{l}\mathbf{T}_{\mathbf{P}} \\
\mathbf{( s )}\end{array}$ & $\begin{array}{l}\mathbf{H}_{\mathbf{S}} \\
\mathbf{( m )}\end{array}$ & $\begin{array}{l}\text { Direction } \\
(\mathbf{d e g})\end{array}$ \\
\hline IWS 1 & 1 & 7.31 & 2.34 & 10.00 \\
\hline IWS 2 & 2 & 9.86 & 2.64 & 0.00 \\
\hline IWS 3 & 3 & 11.52 & 5.36 & -70 \\
\hline IWS 4 & 4 & 12.71 & 2.06 & -10.00 \\
IWS 5 & 5 & 15.23 & 5.84 & 0.00 \\
\hline IWS 6 & 6 & 16.50 & 3.26 & 0.00 \\
\hline IWS - irregular wave states & & & &
\end{tabular}

The $A C C W_{j}$ were calculated for seven U.S. Pacific Coast regions $(j=1: 7)$. Corresponding values for $\Xi_{i j}$ and $\left\langle C_{P}(j)\right\rangle$ are provided in Table 2. Note that the scaling factors do not add to 1 for each location to ensure the average annual wave energy flux for each is correct [14]. 
Table 2. Scaling Factors Used to Calculate the Net ACCW and the Full-Scale Average Annual Wave Energy Flux for the Seven Different Sites

\begin{tabular}{|c|c|c|c|c|c|c|c|}
\hline \multirow[t]{2}{*}{ Sea State } & \multicolumn{7}{|c|}{ Scaling Factors for Each Climate, $\Xi_{i j}$} \\
\hline & 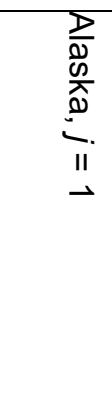 & 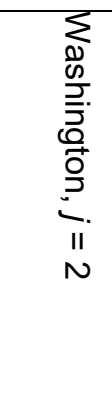 & 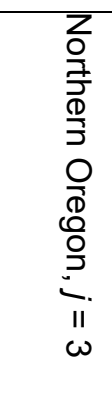 & 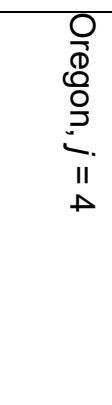 & 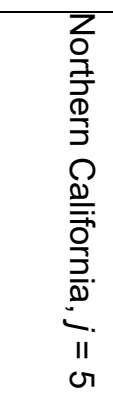 & 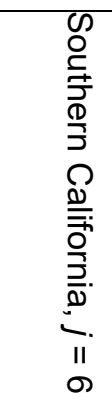 & 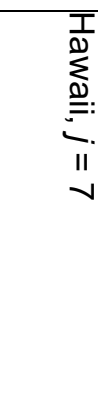 \\
\hline IWS $1, i=1$ & 0.243 & 0.137 & 0.155 & 0.175 & 0.207 & 0.152 & 0.328 \\
\hline IWS $2, i=2$ & 0.332 & 0.277 & 0.307 & 0.268 & 0.230 & 0.270 & 0.245 \\
\hline IWS $3, i=3$ & 0.075 & 0.041 & 0.056 & 0.058 & 0.012 & 0.014 & 0.001 \\
\hline IWS $4, i=4$ & 0.200 & 0.338 & 0.344 & 0.295 & 0.466 & 0.391 & 0.133 \\
\hline IWS $5, i=5$ & 0.024 & 0.022 & 0.037 & 0.034 & 0.16 & 0.010 & 0.0 \\
\hline IWS $6, i=6$ & 0.012 & 0.045 & 0.042 & 0.054 & 0.064 & 0.095 & 0.013 \\
\hline & \multicolumn{7}{|c|}{ Average Annual Wave Energy Flux (kW/m) } \\
\hline$\left\langle\mathrm{C}_{\mathrm{P}}(\mathrm{j})\right\rangle$ & 35.5 & 32.7 & 39.3 & 37.9 & 31.5 & 31.2 & 16.8 \\
\hline
\end{tabular}

Many of the WECs within the prize featured multiple PTOs. The average power absorbed by the WEC, $\langle A P(i)\rangle$, for sea state $\mathrm{i}$ is calculated from test data for each power conversion chain (PTO) of a WEC using:

$$
\overline{P_{k}}=\frac{1}{N} \sum_{m=1}^{N} P_{k_{m}}=\frac{1}{N} \sum_{m=1}^{N} \operatorname{kin}_{k_{m}} d y n_{k_{m}}
$$

where:

- $\overline{P_{k}}$ is the average absorbed power of PTO $k$

- $\quad N$ is the total number of measurements used in the average

- $m$ is the sample number

- $\operatorname{kin}_{k_{m}}$ is the measured kinematic side of power (linear velocity, angular velocity, or volumetric flow rate) for PTO $k$ and sample $m$

- $d y n_{k_{m}}$ is the measured dynamic side of power (force, torque, or differential pressure) for PTO $k$ and sample $m$. 
For the prize, typical measurement duration was 25 minutes (model scale time) with data sampled at $100 \mathrm{~Hz}$. The total average absorbed for sea state $i$ is thus:

$$
\langle A P(i)\rangle=\sum_{k=1}^{Q} \overline{P_{k}}
$$

where $Q$ is the total number of PTOs on the WEC. Inserting and simplifying the prior equations, the final equation for the $A C C W$ at site $j$ is given by:

$$
\operatorname{ACCW}_{j}=\frac{\sum_{i=1}^{n} \Xi_{i j}\left(\sum_{k=1}^{Q}\left(\frac{1}{N} \sum_{m=1}^{N}\left(k_{i n} k_{m} d y n_{k_{m}}\right)\right)\right)}{\left\langle C_{P}(j)\right\rangle}
$$

Finally, the net value for $\overline{A C C W}$ is calculated as a composite average of the average power produced for each of the six IWS sea states for seven different wave sites using:

$$
\overline{A C C W}=\sum_{j=1}^{7} \frac{A C C W_{j}}{7}
$$




\section{Determination of CCE}

Analysis of the WEC archetypes studied in the DOE reference model project concluded that the structural cost (raw material cost plus cost of fabrication and assembly) is the largest individual contributor to LCOE, between $37 \%-52 \%$ [13]. For technologies entering the prize at early TRLs, it was also determined that the structural cost component of the capital costs could be reasonably estimated within the scope and schedule of the prize. Other capital costs of the PTO, mooring system, anchors, umbilical, power electronics, and other non-load-bearing structure were deemed too uncertain to estimate at low TRLs within the scope of the prize; therefore, because these costs contribute less to the LCOE, they were not directly included in the $A C E$ metric. For similar reasons, operations and maintenance costs, such as deployment, operation and maintenance were not included. The $C C E$ is defined as the cost of the load bearing structure, including manufacturing cost. The $C C E$ is a first-order estimate and is defined as:

$$
C C E=\sum_{k=1}^{L} m_{k} \cdot M M C_{k}
$$

where

- $L$ denotes the number of key structural materials that compose the WEC

- $m_{k}$ is the total mass of structural material $k$

- $M M C_{k}$ is the manufactured material cost per unit mass of material $k$

As defined later in this section, the $M M C$ represents all the costs that are included to build the structure at full-scale production. This includes any fabrication or any other manufacturing that is required when building a commercial array. ${ }^{4}$ The structural mass included in the $C C E$ includes the following:

- Any structure that interacts with the wave environment, including any external ballast housing and the ballast itself if determined to be a significant cost contributor

- Any supporting structures used to resist forces in the power conversion chain

- Components central to the load path/force flow path, including power producing and nonpower producing loads (e.g., drag loads) as well as any components of the power conversion chain that are integrated into the structure

- Foundations and components rigidly attached to the WEC that can include structures required to raise or lower a device into the water column (e.g., jack-up barges) and structures required for pre-loading and/or device placement providing reactional reference to the sea bed where the surface area was determined significant by the judges (e.g., gravity bases).

\footnotetext{
${ }^{4}$ While the $A C E$ metric did not include significant capital costs, e.g., the PTO or operations and maintenance costs, these costs were accounted for indirectly through additional criteria within the $H P Q$ metric [3].
} 
For the prize, any WEC designs and components that do not clearly fit the guidelines were evaluated by prize judging panel. For example, personnel or access decks are not required for device operation and therefore would not be considered unless the judges determined the deck is integral to the structural integrity of the hull.

The $C C E$ is calculated for each structural component and grouped by like materials. The $C C E$ is determined by expanding the previous equation for $C C E^{5}$ :

$$
C C E=\sum_{k=1}^{L} \rho_{k} \cdot A_{k} \cdot R S T_{k} \cdot M M C_{k}
$$

where:

- $R S T_{k}$ is the representative structural thickness of material $k$

- $\quad \rho_{k}$ is the density of material of material $k$

- $A_{k}$ is the surface area of material $k$

The reduced-order $C C E$ metric provides an equitable measure that allows for minor variations in design at different stage gates to be quickly accounted for; in the prize, any design changes between stage gates typically required $R S T$ and $M M C$ models to be modified and re-run to account for the structural variations.

\subsection{Determination of RST}

The representative structural thickness $(R S T)$ for each material in the WEC is calculated by:

$$
R S T_{k}=\frac{\sum_{n=1}^{\varepsilon} m_{n}^{k}}{\rho_{k} \cdot \sum_{n=1}^{\varepsilon} A_{n}^{k}}
$$

where,

- $\varepsilon$ is the number of components that are manufactured from material $k$

- $m_{n}^{k}$ is the mass of each component $\mathrm{n}$ that is made of material $k$

- $A_{n}^{k}$ is the simplified surface area of component $n$ of material $k$

The simplified surface area $A_{n}^{k}$ is used to approximate the geometry of component $n$. To ensure equitable modelling of all components, all stiffeners and support members that do not directly contribute to the power conversion path (from wave force to PTO) are excluded from area $A_{n}^{k}$.

\footnotetext{
${ }^{5}$ The definitions of RST and MMC are used in the prize because many teams will not have performed a detailed LCOE estimate or did not have the time and sufficient information to perform such a detailed cost estimate.
} 
Figure 3 and Figure 4 show how the surface area is simplified for Reference Model \#3 (RM3) [6].
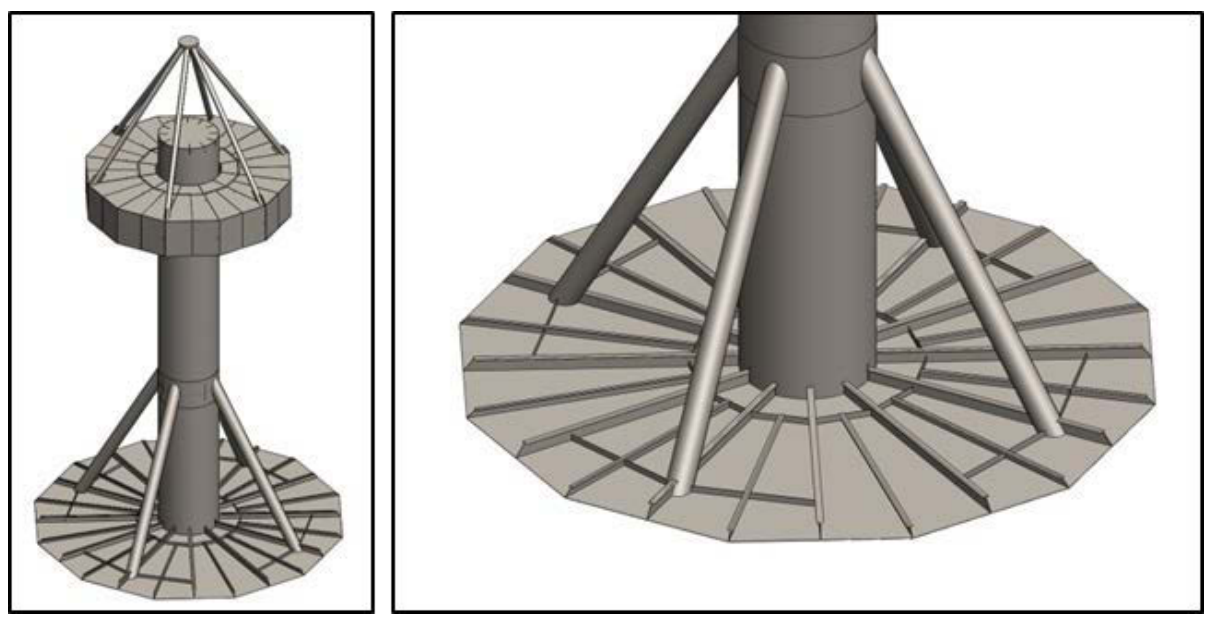

Figure 3. Original DOE RM3 geometry
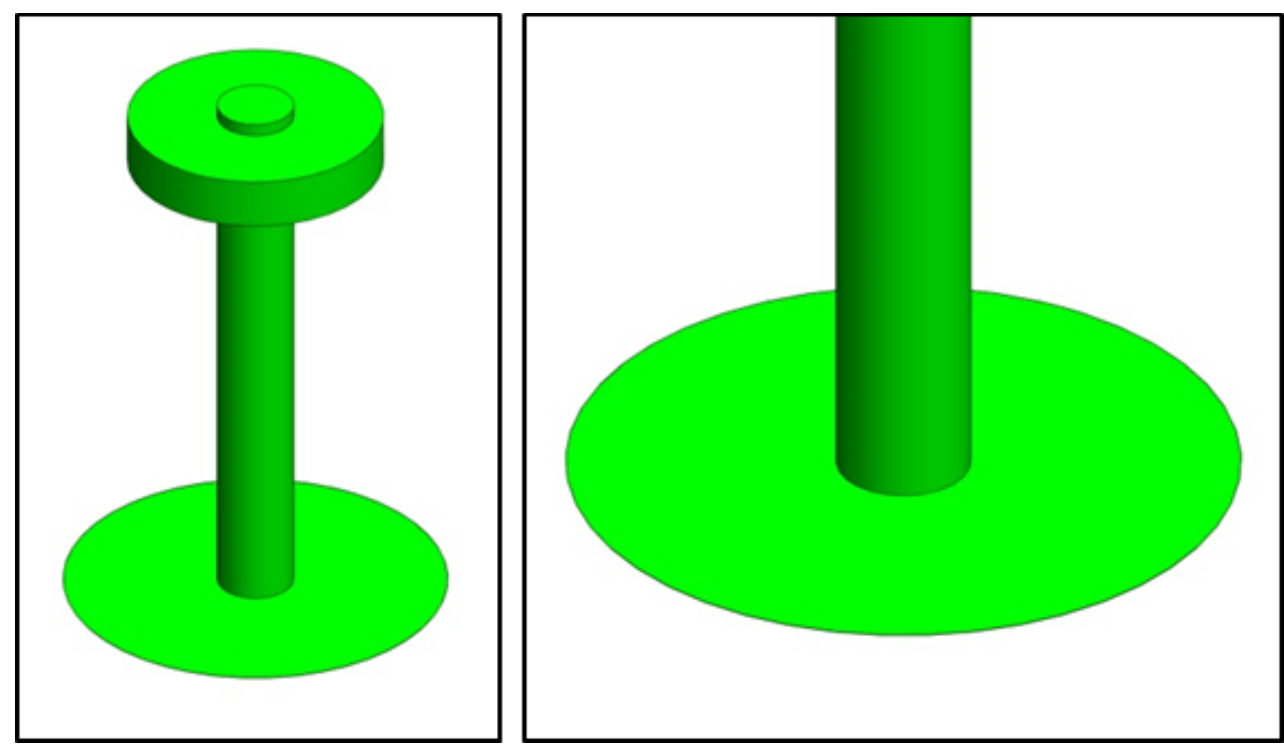

Figure 4. Simplified DOE Reference Model geometry

As per the prize rules [3], $R S T$ is a scalar quantity that is used to determine the total structural mass when multiplied by the surface area of the device. $R S T$ is a single uniform thickness used to approximate the representative material thickness of each simplified component. $R S T$ can be visualized by melting down the structure of a component and "casting" it in the simplified shape. This means that all stiffeners and support structures are "lumped" together. A simple representation of the $R S T$ is shown in Figure 5 with a flat plate. The original structure includes a grid of stiffeners with a thin hull. That same quantity of material is then represented by a solid plate with the thickness given by the RST. 


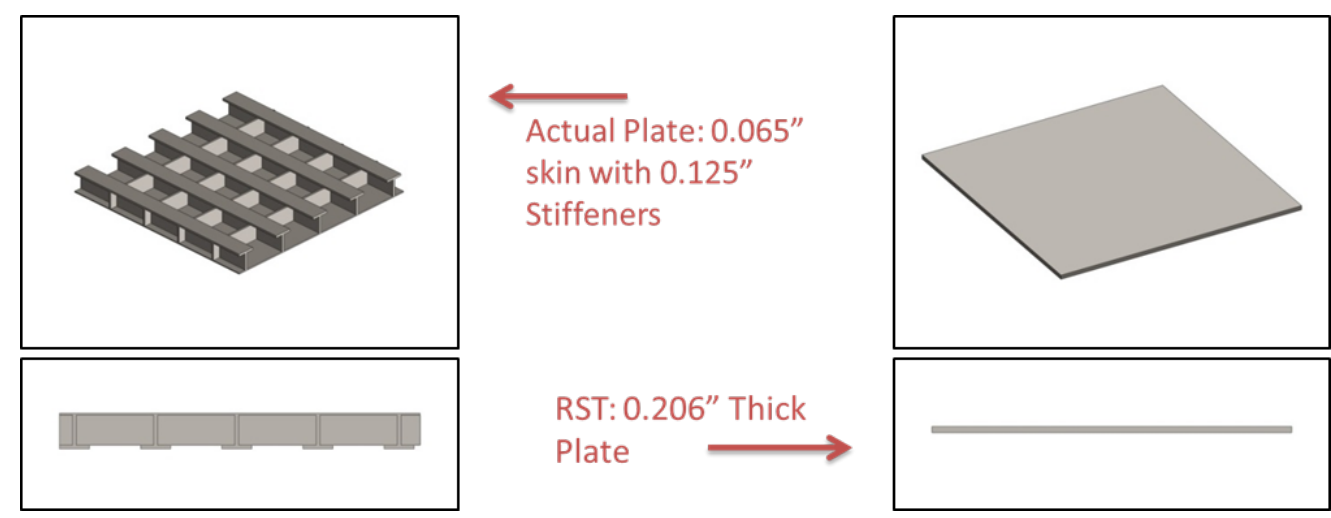

Figure 5. Visual representation of the RST concept for a component originally composed of plate and beams. All the material from the plate and beam structure (left) are distributed equally as a simple plate over the simplified surface area (right).

\subsubsection{Loads Analysis used to Calculate $m_{n}^{k}$}

The mass of each component $m_{n}^{k}$ within the $R S T$ calculation was determined using a simplified stress analysis. Structural models were chosen for each component of each WEC based on complexity. The simplest/lowest-order structural models that provided an accurate result were chosen. Nearly all components were evaluated with a yield stress-driven structural analysis; however, for composite structural components (i.e., filament wound fiberglass), a strain-driven analysis was undertaken to account for the primary failure mode observed in large-scale fiberglass structures (e.g., wind turbine blades) [15]. Details on the structural analysis calculations are as follows:

1. All hydrodynamic design loads were specified for a $2.25 \mathrm{~m}$ monochromatic wave representative of loads from the top $70^{\text {th }}$ percentile waves at Humboldt Bay, California. ${ }^{6}$

2. For structures with regular shapes, equivalent beam and flat plate models were used with the critical stress locations and failure modes identified.

3. For more complex structures, finite element stress models were used with the critical stress locations and failure modes identified.

4. When composite structures were utilized, coupon-level yield stress was not used, but instead a strain-driven stress limitation was used. Blade testing performed at the National Renewable Energy Laboratory and thick (93-mm) coupon tests performed at Montana State University have shown that E-Glass/Epoxy composite structures fail at 3\% strain [15].

\footnotetext{
${ }^{6}$ From experience on the DOE Reference Model project, it was found that the critical load cases typically result during device operation $[6,24]$. Further, many WECs utilize a non-power-producing storm survival mode or a power producing load shedding mode (a similar idea to how wind turbine rotor blades feather) to reduce or avoid of extreme loads. Thus, this $70^{\text {th }}$ percentile operational wave condition was applied for the loads analysis of all WEC components.
} 
5. The structural mass for each component, $m_{n}^{k}$, was determined by an iterative procedure where the thickness of the critical structural component was identified that allows the structure to meet the specified safety factor.

6. For each WEC component, the structural analysis was run for three scenarios: Low/Medium/High corresponding to structural safety factors of 1.5/1.75/2.0, respectively. For each of these Low/Medium/High scenarios, a corresponding $R S T$ was calculated.

7. For each WEC component, the judging panel evaluated video footage from the MASK tests to guide their determination of the most appropriate $R S T$ value (Low/Medium/High) based on observation of the device operation.

\subsection{Determination of MMC}

The manufactured material cost, $M M C$, is a scalar value that represents the total cost to manufacture the components at full production scale on a per unit mass basis. The $M M C$ includes raw material cost, fabrication, forming, and assembly.

The MMC methodology follows typical conventions often used in estimating structural capital costs at early project stages by lumping raw material costs with typical manufacturing costs and specified as dollars per tonne. In many industries, these values are well established for different materials and manufacturing methods based on years of experience and many commercial fullscale builds. The wave energy sector does not have the long history to develop the empirical rules of thumb. Therefore, for the prize, when CCE values were not available, CCE values were based on typical construction, or manufacturing costs of structures of similar size and complexity using like materials from other industries. For example, many steel WECs utilize relatively simple geometries (i.e., cylinders, flat plate sections, etc.) made of subsections that can reach upwards of $50 \mathrm{~m}$ in length. Land-based and offshore wind towers are relatively well-known structures that typically have base diameters of 6 to $8 \mathrm{~m}$ and are between 80 and $100 \mathrm{~m}$ tall. The towers are made by rolling and welding steel sections (cans) that are between 20 and $30 \mathrm{~m}$ tall. These sections are separately transported and joined together onsite, similar to how WEC sections may be fabricated and shipped to a harbor for assembly. Towers will generally have stiffened sections, access doors, ladders, and other equipment that would be anticipated on WECs. The National Renewable Energy Laboratory has collected cost data that suggest the cost per unit weight for these structures is on the order of $\$ 3,000 /$ tonne or $\$ 3 / \mathrm{kg}$. Another example from the wind industry that has direct relevance to the WEC sector is the cost of hand-laid fiberglass (epoxy, e-glass) blades. Once blades are produced at large enough volumes where tooling costs can be amortized across many blades, the raw material costs make up approximately $30 \%-40 \%$ of the total cost. This translates to the MMC of approximately $\$ 7.80-$ $9.80 / \mathrm{kg}[16]$.

The $M M C$ values were selected using a combination of both public and internal offshore wind cost models [17], reference cost models [18, 19, 20], the National Renewable Energy Laboratory cost and scaling model [21], , cost estimates for like structures (i.e., structures that utilize the material of interest that can be built at similar scale), and cost estimates from manufacturers. The values used are not intended to replace more detailed cost models and/or fabrication quotes, but 
for the purposes of the prize, they provide expedient comparison and consistency across different WEC device types.

Each material used in the prize was evaluated in an equivalent manner to determine a range of cost estimates. Of the nine prize finalist WECs, seven materials were used. Table 3 shows the list of $M M C$ values used for each material in the prize. In practice, the value of $M M C$ can be affected by material suppliers, complexity of manufacturing, number of subsystems to be assembled into the devices, as well as other intangible factors ${ }^{7}$. For these reasons, three values were used (low, med, high) and the Judging panel selected the appropriate $M M C$ value for each WEC component.

Table 3. MMC Values Used to Evaluate CCE for Each WEC in the Prize

\begin{tabular}{lrrr}
\hline Material & Low & Med & High \\
\hline Steel - A36 & $\$ 2,250$ & $\$ 3,000$ & $\$ 4,500$ \\
\hline Steel Reinforced Concrete & $\$ 424$ & $\$ 510$ & $\$ 557$ \\
\hline $\begin{array}{l}\text { High-density Polyethylene } \\
\text { (HDPE) }\end{array}$ & $\$ 6,000$ & $\$ 7,900$ & $\$ 12,000$ \\
Coated Fabric & $\$ 7,200$ & $\$ 9,500$ & $\$ 13,500$ \\
Aluminum - 5083 & $\$ 4,900$ & $\$ 5,900$ & $\$ 8,000$ \\
\hline Fiberglass (E-Glass/Epoxy) & $\$ 7,500$ & $\$ 8,200$ & $\$ 9,500$ \\
\hline Filament Wound Fiberglass & $\$ 4,630$ & $\$ 5,510$ & $\$ 6,620$ \\
\hline
\end{tabular}

$M M C$ estimates provide an expedient method for evaluating the feasibility of low-TRL technologies, but fabricator estimates or quotes will generally provide more certainty in the cost estimate. Thus, whenever available, a quote from a reputable and experienced manufacturer should be used for the value of $C C E$.

\footnotetext{
${ }^{7}$ It is not uncommon for MMC values to have a wide range due to factors such as device complexity, manufacturer location, profit margins, time of year, and several other factors that have little to do with the WEC technology. Sensitivity studies of the MMC to the parameters used can provide valuable insight into the relationship of cost with design choices. This is particularly true when considering options for different materials and different structural designs.
} 


\section{Determination of HPQ Factors}

The scale factor used in the $H P Q$ metric is composed of six impact factors that are determined from the MASK testing. The impact factors are derived from performance metrics evaluated through measurement of a variable, the count of an event, or visual observation. Based on the performance metrics, each of the impact factors was assigned one of five values as defined in the rules [3] and shown in Table 4. These values ranged from less than unity to account for poor and lower than average performance and greater than unity to account for strong and above average performance. A value for each performance metric was determined for each team. For each performance metric, the range of values (for all teams) were mapped to the range of impact factors. The value of the impact factor closest to a team's performance metric was chosen as the impact factor ${ }^{8}$.

Table 4. Impact Factors Used in the HPQ Weighting of $A C E$

\begin{tabular}{clllll}
\hline $\boldsymbol{H P Q}$ Impact Factor & $\mathbf{1}$ & $\mathbf{2}$ & $\mathbf{3}$ & $\mathbf{4}$ & $\mathbf{5}$ \\
\hline$I_{M F}$ & 0.92 & 0.96 & 1.0 & 1.04 & 1.08 \\
$I_{W C}$ & 0.96 & 0.98 & 1.0 & 1.02 & 1.04 \\
$I_{A P_{P 2 A}}$ & 0.92 & 0.96 & 1.0 & 1.04 & 1.08 \\
$I_{E S}$ & 0.92 & 0.96 & 1.0 & 1.04 & 1.08 \\
$I_{R S}$ & 0.90 & 0.95 & 1.0 & 1.05 & 1.1 \\
$I_{A C}$ & 0.92 & 0.94 & 0.96 & 0.98 & 1.0 \\
\hline
\end{tabular}

The $H P Q$ impact factors were derived from the MASK test results using 10 sea states. These sea states comprised the six unidirectional long-crested wave states (irregular waves, IWS) specified in Table 1 with two additional storm sea states (large irregular waves, LIWS) and two additional multi-directional sea states (realistic waves, RWS). These four additional sea states include directional spectrum spreading. The full-scale properties of the four sea states used for the $H P Q$ impact factor determination are summarized in Table 5, where $s$ is the wave spreading function based on $\cos ^{2 \mathrm{~s}}[22]$.

\footnotetext{
${ }^{8}$ A fixed scale relating the impact factors to measurements was not included in the rules and the judges therefore decided to use a relative weighting between teams.
} 
Table 5. Full-Scale Properties of the Additional Four Sea States Used to Calculate the HPQ

\begin{tabular}{lllllll}
\hline $\begin{array}{l}\text { Wave } \\
\text { Designation }\end{array}$ & $\begin{array}{l}\text { Wave Ref } \\
\text { Number, } \boldsymbol{i}\end{array}$ & $\begin{array}{l}\boldsymbol{T}_{\boldsymbol{P}} \\
\mathbf{( s )}\end{array}$ & $\begin{array}{l}\boldsymbol{H}_{\boldsymbol{S}} \\
(\mathbf{m})\end{array}$ & $\begin{array}{l}\text { Direction } \\
(\mathbf{d e g})\end{array}$ & $\boldsymbol{s}$ & $\boldsymbol{\gamma}$ \\
\hline LIWS 1 & 7 & 13.9 & 7.9 & -30.0 & 3.0 & 3.3 \\
\hline LIWS 2 & 8 & 11.2 & 9.2 & -70.0 & 7.0 & 3.3 \\
RWS 1 & 9 & 14.38 & 1.52 & -70.0 & 7.0 & 2 \\
& & 7.18 & 2.16 & 0.0 & 10.0 & 2 \\
\hline RWS 2 & 10 & 14.83 & 1.58 & -70.0 & 7.0 & 2 \\
& & 8.65 & 1.30 & -10.0 & 10.0 & 2 \\
\hline
\end{tabular}

Details and definitions for the five performance metrics and corresponding impact factors are given in the following subsections.

\subsection{Statistical Peak of Mooring Forces}

Mooring line tensions were simultaneously measured for each mooring line of each WEC for all wave conditions. The peak tension in the mooring lines is an indicator of the mooring line cost with the implication that larger forces increase cost and smaller forces decrease cost. The statistical peak of the mooring line force for a single mooring line was calculated as average of the largest $5 \%$ of the peak mooring line tension for that line. The overall statistical peak of the mooring line force for the WEC was the largest value from the individual lines:

$$
M F_{i}=\max \left(\overline{\overline{\operatorname{Hist}\left(F_{q_{l, n}}\right)_{96-100}}}\right)
$$

where $M F_{i}$ is the statistical peak of the mooring line force for wave $i, F_{q_{i, n}}$ is the $\mathrm{n}^{\text {th }}$ peak of the tension in mooring line $q$ for wave $i$, and $\operatorname{Hist}(x)_{96-100}$ denotes the values in the histogram of $x$ from the $96^{\text {th }}$ to the $100^{\text {th }}$ percentile. Each mooring line signal was separately low-pass filtered (filter order and cut-off were selected by the data analysts to eliminate noise and ripple while minimizing signal loss) to remove sample jitter, and a peak-finding algorithm was used to identify the peaks in the time series. The total statistical peak of the mooring line force was then calculated using:

$$
M F=0.2 \frac{\sum_{j=1}^{7} \sum_{i=1}^{6} \Xi_{i j} M F_{i}}{7}+0.6 \frac{\sum_{i=7}^{8} M F_{i}}{2}+0.2 \frac{\sum_{i=9}^{10} M F_{i}}{2}
$$

where $j$ is the site, $i=1: 6$ are the IWS sea states (as before), $i=7: 8$ are the LIWS sea states, and $i=9: 10$ are the RWS sea states. From the impact factors given in Table 4, the WEC with the lowest value of $M F$ was assigned $I_{M F}(5)$, and the WEC with the highest value was assigned $I_{M F}(1)$. WECs with statistical peak of mooring line forces falling between the minimum and maximum values were linearly mapped to the closest impact factor.

\subsection{Statistical Peak of Mooring Watch Circle}

The mooring watch circle is a circle centered at the undisturbed location of the WEC with a radius equal to the maximum horizontal excursion of the WEC measured from the center of the 
undisturbed location. The WEC excursions measured during testing provide a proxy measure for device spacing with the implication that larger spacing increases costs and smaller spacing will decrease cost. To calculate the mooring watch circle, the positions of each rigid body that comprise the WEC were measured. Position measurements were started prior to the waves to provide a measure of the undisturbed location. The statistical peak of the mooring watch circle was calculated as the average of the largest $5 \%$ of the peak horizontal displacements for wave $i$ of a point on the primary body:

$$
W C_{i}=\overline{\overline{H \imath s t(Y)_{96-100}}}
$$

where $Y=\sqrt{X^{2}+Y^{2}}$ denotes the horizontal distance from the WEC's undisturbed location. The total statistical peak of the mooring watch circle was calculated using:

$$
W C=0.2 \frac{\sum_{j=1}^{7} \sum_{i=1}^{6} \Xi_{i j} W C_{i}}{7}+0.6 \frac{\sum_{i=7}^{8} W C_{i}}{2}+0.2 \frac{\sum_{i=9}^{10} W C_{i}}{2}
$$

From the impact factors given in Table 4, the WEC with the smallest statistical peak of the mooring watch circle was assigned $I_{W C}(5)$, and the WEC with the largest value was assigned $I_{W C}(1)$. WECs with statistical peak of the mooring watch circle that fell between the minimum and maximum values were linearly mapped to the closest impact factor.

\subsection{Statistical Peak-to-Average Ratio of Absorbed Power}

WECs are unusual among renewable power generating systems because generators typically do not run at a constant speed; instead, the generator speed can change significantly and even reverse direction during a wave cycle. The ratio of the statistical peak power to average power captures the cost impact of the oscillating generator speed. A large ratio implies that the generator will be operating well below rated capacity, which decreases efficiency and increases cost per energy unit. The statistical peak-to-average ratio of absorbed power was calculated as the average of the largest 5\% of the gross WEC peak power for wave i divided by the average power, $P_{j}$ :

$$
Q P_{P 2 A, i}=\frac{\overline{\overline{\operatorname{Hist}(P)_{96-100}}}}{\bar{P}_{J}}
$$

The total statistical peak-to-average ratio of absorbed power was calculated using:

$$
Q P_{P 2 A}=0.6 \frac{\sum_{j=1}^{7} \sum_{i=1}^{6} \Xi_{i j} Q P_{P 2 A, i}}{7}+0.1 \frac{\sum_{i=7}^{8} Q P_{P 2 A, i}}{2}+0.3 \frac{\sum_{i=9}^{10} Q P_{P 2 A, i}}{2}
$$

From the impact factors given in Table 4, the WEC with the smallest peak-to-average ratio was assigned $I_{A P_{P 2 A}}(5)$, and the WEC with the largest value was assigned $I_{A P_{P 2 A}}(1)$. WECs with peak-to-average ratios that fell between the minimum and maximum values were linearly mapped to the closest impact factor. 


\subsection{End-Stop Impact Events}

Many WEC designs feature PTOs that have maximum motion constraints known as "end-stops" (ES). Because of this, end-stop impacts can occur during extreme events or during other conditions when the WEC may not be properly operating. End-stop impacts indicate that stronger structures will be needed, and higher fatigue loads are likely, thus driving up costs. Endstop impacts are counted as the number of times the WEC touches the end-stop or passes the end-stop threshold; thus, $E S_{q_{i}}$ is the number of end-stop impacts counted for absorber q and wave $i$. For WECs with multiple absorbing elements, the number of end-stop impacts is counted for each element and the element with the largest count is taken as the value for $E S_{i}$ :

$$
E S_{i}=\max \left(E S_{q_{i, n}}\right)
$$

The total end-stop impact measurement is then:

$$
E S=0.4 \frac{\sum_{j=1}^{7} \sum_{i=1}^{6} \Xi_{i j} E S_{i}}{7}+0.2 \frac{\sum_{i=7}^{8} E S_{i}}{2}+0.4 \frac{\sum_{i=9}^{10} E S_{i}}{2}
$$

From the impact factors given in Table 4, WECs that exhibited no impact events were assigned $I_{E S}(5)$ while the WEC with the highest value of $E S$ was assigned $I_{E S}(1)$. WECs with end-stop events that fell between 0 and the maximum count were linearly mapped to the closest impact factor.

\subsection{Absorbed Power in Realistic Seas}

Two multidirectional wave sets were specified, RWS 1 and RWS 2, so that a WEC's ability to absorb power in such seas could be characterized in contrast to its ability to absorb power in similar unidirectional waves. The absorbed power in realistic seas was calculated as the ratio of the absorbed power from the WEC in RWS 1 to IWS 2 and RWS 2 to IWS 4:

$$
R S=\frac{\frac{\left\langle A P\left(i_{R W S 1}\right)\right\rangle}{\left\langle A P\left(i_{I W S 2}\right)\right\rangle}+\frac{\left\langle A P\left(i_{R W S 2}\right)\right\rangle}{\left\langle A P\left(i_{I W S 4}\right)\right\rangle}}{2}
$$

From the impact factors given in Table 4, the WEC with the ratio of the absorbed power closest to unity was assigned $I_{R S}(5)$, and the WEC with the largest deviation from unity was assigned $I_{R S}(1)$. WECs with a ratio of the absorbed power that fell between unity and the maximum deviation were linearly mapped to the closest impact factor.

\subsection{Adaptive Control Effort}

The adaptive control effort factor was assigned based on the control effort and assumed cost as observed in testing and as was outlined in the technical submission. The WEC with the simplest controller in terms of the number of measurements, the complexity of measurements, cost of measurements, computational requirements, and device operation was assigned $I_{R S}(5)$. The WEC with the most complex controller was assigned $I_{R S}(1)$, and WECs with intermediate control complexities and costs were assigned the intermediate factors by the judging panel. 


\section{1:20 Scale Testing Overview}

The MASK basin is an indoor wave basin having an overall length of 360 feet, a width of 240 feet, and a depth of 20 feet except for a 35-foot deep trench that is 50 feet wide and parallel to the long side of the basin (Figure 6). The basin is spanned by a 376-foot bridge supported on a rail system that permits the bridge to transverse to the center of the basin width, as well as to rotate up to 45 degrees from the centerline. The wavemaker system consists of 216 paddles. There are 108 paddles along the north edge of the basin, 60 paddles in a 90-degree arc, and 48 paddles along the west edge of the basin. The large number and orientation of the wave makers allows for a wide range of multidirectional polychromatic waves to be generated, yielding capabilities to produce complex waves. The 0 and -70 degree wave directions are shown in Figure 7. 

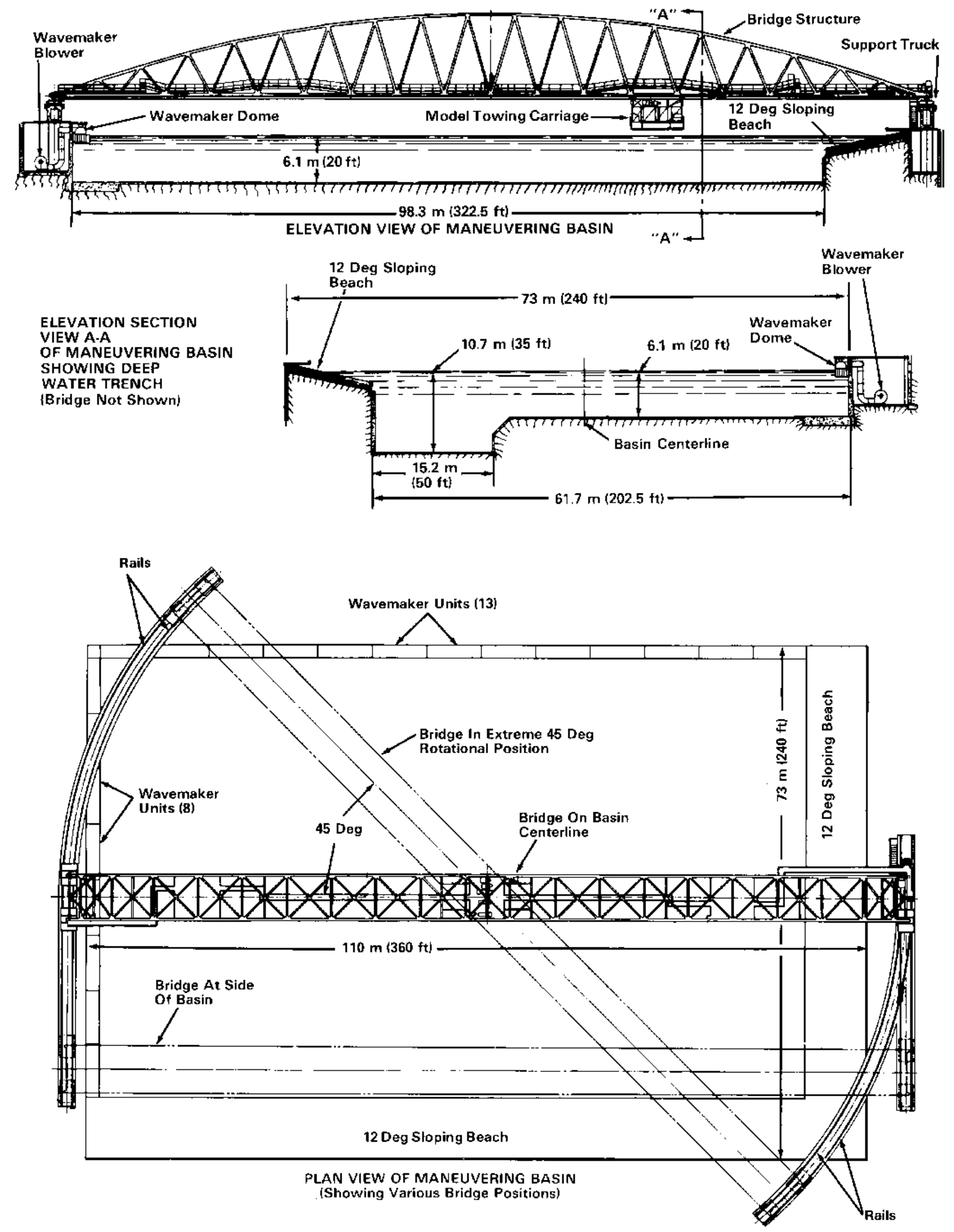

Figure 6. General schematic of bridge and MASK basin; note: this drawing shows a previous version to the recently installed 216 wave paddle system 


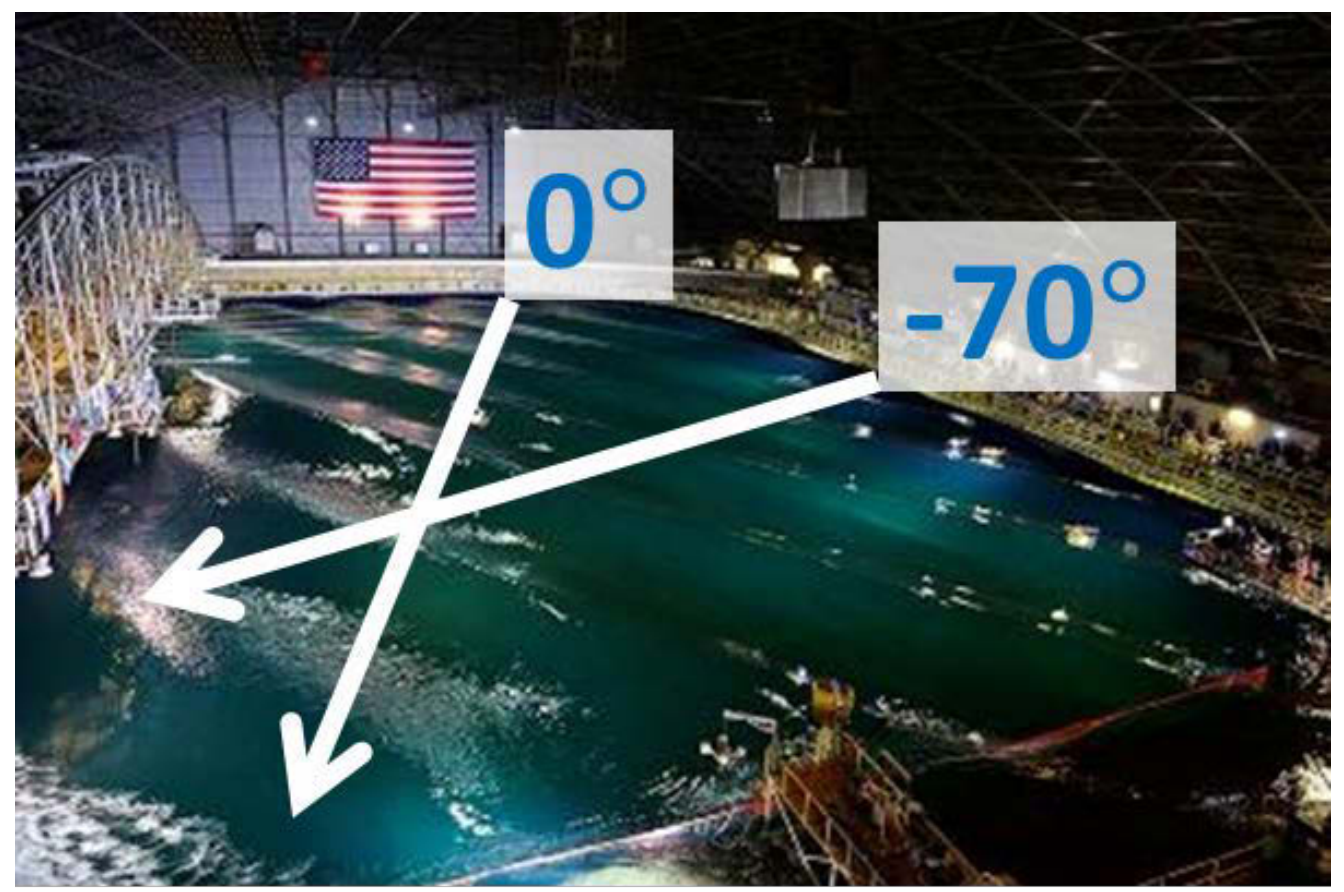

Figure 7. MASK basin with arrows depicting the direction of wave propagation

Each team had two consecutive weeks at MASK. During the first week, each team assembled its WEC outside the basin, and the Prize Administration Team and test lead verified dimensional compliance and sensor performance. During the second week, the WEC was deployed, tested, and recovered. Tests were conducted sequentially with a one week overlap between teams (while one team was testing, another was assembling), leading to a 10-week test program.

\subsection{Sea States}

During tests in the MASK basin, each WEC was subjected to the 10 irregular wave states summarized in Table 6 [14]. These wave parameters were used with the Joint North Sea Wave Project (JONSWAP) spectrum to synthesize the wave time-series used in the competition. The $A C C W$ was calculated from the six unidirectional long-crested irregular wave states (IWS) that are representative of the West Coast of the United States, including Alaska and Hawaii [3, 14]. The $H P Q$ was calculated for all 10 sea states. The IWS sea states were assigned a JONSWAP gamma value of 1 for each of the spectra (e.g., a Bretschneider spectrum), the LIWS spectra used gamma $=3.3$ (more peaked), and the RWS spectra used gamma $=2$. 
Table 6. Parameters for the 10 1:20 Scale Sea States. Direction is Specified Relative to the Forward-Facing Direction of the WEC [deg] and Spreading is Based on $\cos ^{2 s}$

\begin{tabular}{lrrrr}
\hline $\begin{array}{l}\text { Wave } \\
\text { Designation }\end{array}$ & $\begin{array}{r}\boldsymbol{T}_{\boldsymbol{P}} \\
(\mathbf{s})\end{array}$ & $\begin{array}{r}\boldsymbol{H}_{\boldsymbol{S}} \\
(\mathbf{m})\end{array}$ & $\begin{array}{r}\text { Dir } \\
(\mathbf{d e g})\end{array}$ & $\mathbf{s}$ \\
\hline IWS 1 & 7.31 & 2.34 & 10 & none \\
\hline IWS 2 & 9.86 & 2.64 & 0 & none \\
\hline IWS 3 & 11.52 & 5.36 & -70 & none \\
\hline IWS 4 & 12.71 & 2.05 & -10 & none \\
\hline IWS 5 & 15.23 & 5.84 & 0 & none \\
\hline IWS 6 & 16.50 & 3.25 & 0 & none \\
\hline LIWS 1 & 13.9 & 7.9 & -30 & 3 \\
\hline LIWS 2 & 11.2 & 9.2 & -70 & 7 \\
\hline RWS 1 & 14.38 & 1.52 & -70 & 7 \\
& 7.18 & 2.16 & 0 & 10 \\
\hline RWS 2 & 14.83 & 1.59 & -70 & 7 \\
& 8.65 & 1.30 & -10 & 10 \\
\hline
\end{tabular}

All WECs were moored to ensure they had the same undisturbed location in the wave basin, centered underneath the carriage. Prior to testing, the wave maker was tuned so that each wave spectrum closely matched the spectrum of the specified sea state within the limits of the wave maker. To do this, an array of 12 ultrasonic wave probes was located underneath the carriage and judiciously placed to cover the range of expected WEC positions that may occur during testing. These 12 probes were removed during testing because the WEC and supporting wiring would interfere with measurement. Thus, three other sets of five wave probes were positioned upstream to provide wave measurement during testing. These 15 probes were located at least $17 \mathrm{~m}$ from the carriage so that the wave field would be minimally affected by the WEC under test.

During calibration runs with no WEC in the basin, time series of the water surface elevations were simultaneously recorded at $50 \mathrm{~Hz}$ by all 27 wave probes during the calibration runs. The 12 wave probes under the bridge provided the calibration data, and the 15 upstream probes measured the baseline wave fields used for test data quality assurance. Refer to Appendix C for an analysis of the spatial variability in the waves from the 12 wave probes in the test area.

The significant wave height, $H_{S}$, the wave energy flux, $J$, and the wave energy period, $T_{E}$ were calculated for each wave probe and each test wave as follows: 


$$
\begin{gathered}
H_{S}=4 \sqrt{m_{0}} \\
J=\rho g \sum_{k=f_{0}}^{f_{N}} S\left(f_{k}\right) c_{g}\left(f_{k}\right) \Delta f \\
T_{e}=\sqrt{\frac{m_{-1}}{m_{0}}}
\end{gathered}
$$

where $S\left(f_{k}\right)$ is the spectral density at frequency $f_{k}, c_{g}\left(f_{k}\right)$ is the group velocity at frequency $f_{k}$, $\Delta f$ is the frequency resolution of the spectra, $g$ is the gravitational constant, $\rho$ is the density of water, and the spectral moment is:

$$
m_{j}=\sum_{k=f_{0}}^{f_{N}} f_{k}^{j} S\left(f_{k}\right) \Delta f
$$

For each of the 10 sea states, the average value of the 12 wave probes and the standard deviation between the individual values of the wave probes were calculated, $H_{S}, J$, and $T_{E}$ (Table 7). The typical standard deviation of the significant wave height to average significant wave height for each wave set was less than $1 \%$ with a maximum value of $1.6 \%$. The wave energy flux and period also showed similar consistency within the test area with typical standard deviation to average being less than $1.5 \%$ and $1.6 \%$, respectively. The wave field was consistent throughout the test area under the carriage and the wave makers successfully reproduced the specified spectra for all but the storm waves.

Table 7. Average and Standard Deviation between the 12 Wave Probes for the Wave Height, Energy Flux, and Energy Period within the Test Area for all 10 Test Sea States Measured Underneath the Carriage at the WEC Deployment Location.

\begin{tabular}{lllllll}
\hline $\begin{array}{l}\text { Wave } \\
\text { Designation }\end{array}$ & $\begin{array}{l}\overline{H_{\boldsymbol{S}}} \\
(\mathbf{m})\end{array}$ & $\begin{array}{l}\boldsymbol{\sigma}_{\overline{\boldsymbol{H}_{\boldsymbol{S}}}} \\
\mathbf{( m )}\end{array}$ & $\begin{array}{l}\overline{\boldsymbol{J}} \\
\mathbf{( W / m})\end{array}$ & $\begin{array}{l}\boldsymbol{\sigma}_{\overline{\boldsymbol{J}}} \\
\mathbf{( W / m})\end{array}$ & $\begin{array}{l}\overline{\boldsymbol{T}_{\boldsymbol{E}}} \\
(\mathbf{s})\end{array}$ & $\begin{array}{l}\boldsymbol{\sigma}_{\overline{T_{E}}} \\
(\mathbf{s})\end{array}$ \\
\hline IWS 1 & 0.125 & 0.0009 & 11.1 & 0.145 & 1.49 & 0.033 \\
\hline IWS 2 & 0.142 & 0.0006 & 18.5 & 0.148 & 1.90 & 0.004 \\
\hline IWS 3 & 0.277 & 0.0039 & 84.6 & 0.921 & 2.27 & 0.087 \\
\hline IWS 4 & 0.108 & 0.0007 & 13.9 & 0.146 & 2.40 & 0.005 \\
\hline IWS 5 & 0.318 & 0.0023 & 158.6 & 2.49 & 2.99 & 0.019 \\
\hline IWS 6 & 0.165 & 0.0014 & 45.4 & 0.776 & 3.13 & 0.004 \\
\hline LIWS 1 & 0.391 & 0.0055 & 217.7 & 5.19 & 2.83 & 0.061 \\
\hline LIWS 2 & 0.411 & 0.0046 & 193.6 & 3.201 & 2.47 & 0.117 \\
\hline RWS 1 & 0.138 & 0.0022 & 18.7 & 0.389 & 1.98 & 0.0251 \\
\hline RWS 2 & 0.101 & 0.0003 & 12.4 & 0.108 & 2.40 & 0.016 \\
\hline
\end{tabular}


Equitable testing between teams requires that all waves must be repeatable across tests.

Therefore, for each sea state, the same wave parameters and phases were used for all tests to ensure each team experienced the same wave time series. Appendix $\mathrm{C}$ shows a comparison of wave measurements for four random teams using the capacitive wave probes located $17 \mathrm{~m}$ ahead of the WEC test area. The results demonstrate that the waves are highly repeatable between tests.

\subsection{Testing}

Each test run was about 50 minutes with $10-20$ minutes allocated between runs for basin settling and to allow configuration changes - both physical configuration changes and control adjustments were allowed. The schedule of events is given in Table 8 . The tuning stage allowed teams to adjust their control settings or allow their adaptive controller to self-tune. Thereafter, teams could not interact with their WEC. Teams could also elect to skip this step. The 25-minute interval for testing provided a sufficient window to ensure stationarity.

Table 8. Breakdown and Duration of Each Wave Test

\begin{tabular}{ll}
\hline Event & time from $\mathbf{~ = ~} \mathbf{0}$ (start of test) \\
\hline Start-up (time for waves to fully develop) & $0-5 \mathrm{~min}$ \\
$\begin{array}{l}\text { Optional tuning (teams tune their controller and PTO } \\
\text { settings for the waves) }\end{array}$ & $5-15 \mathrm{~min}$ \\
Testing (data to be used for ACE calculation) & $15-40 \mathrm{~min}$ \\
Basin settling, re-configuration as needed, data checks & $40-60 \mathrm{~min}$ \\
\hline
\end{tabular}

To evaluate and verify stationarity in the wave field statistics regardless of the start time for the 25-minute analysis window, the significant wave height, wave energy flux, and wave energy period were calculated for each sea state using three different 25-minute windows, each successively starting 5 minutes after the prior one, so data overlapped by 5 minutes at most — the first stated at 5 minutes, the second at 10 minutes and the third at 15 minutes. The standard deviation values for $\overline{H_{S}}$ and $T_{E}$ were typically less than $1 \%$ of the averages for the different windows while the standard deviation values for $\bar{J}$ were typically less than $3 \%$ as shown in Table 9. 
Table 9. Average and Standard Deviation of the Wave Height, Energy Flux and Energy Period of the Three 25-Minute Window Data Sets with Start Times Staggered by 5 Minutes within the Test Area for all 10 Test Waves Calculated.

\begin{tabular}{lllllll}
\hline $\begin{array}{l}\text { Wave } \\
\text { Designation }\end{array}$ & $\begin{array}{l}\overline{H_{S}} \\
(\mathbf{m})\end{array}$ & $\begin{array}{l}\boldsymbol{\sigma}_{\overline{H_{S}}} \\
(\mathbf{m})\end{array}$ & $\begin{array}{l}\overline{\boldsymbol{J}} \\
\mathbf{( W / m )}\end{array}$ & $\begin{array}{l}\boldsymbol{\sigma}_{\overline{\boldsymbol{J}}} \\
\mathbf{( W / m})\end{array}$ & $\begin{array}{l}\overline{T_{E}} \\
(\mathbf{s})\end{array}$ & $\begin{array}{l}\boldsymbol{\sigma}_{\overline{T_{E}}} \\
(\mathbf{s})\end{array}$ \\
\hline IWS 1 & 0.123 & 0.0012 & 10.7 & 0.254 & 1.48 & 0.008 \\
\hline IWS 2 & 0.139 & 0.0029 & 17.7 & 0.665 & 1.90 & 0.007 \\
\hline IWS 3 & 0.273 & 0.0022 & 82.0 & 0.975 & 2.27 & 0.006 \\
\hline IWS 4 & 0.109 & 0.0003 & 14.2 & 0.222 & 2.43 & 0.024 \\
\hline IWS 5 & 0.319 & 0.0027 & 159.8 & 4.42 & 3.04 & 0.032 \\
\hline IWS 6 & 0.166 & 0.0015 & 46.0 & 1.39 & 3.19 & 0.035 \\
\hline LIWS 1 & 0.392 & 0.0052 & 216.5 & 6.68 & 2.83 & 0.011 \\
\hline LIWS 2 & 0.371 & 0.0019 & 157.1 & 1.411 & 2.41 & 0.003 \\
\hline RWS 1 & 0.138 & 0.0004 & 18.5 & 0.178 & 1.98 & 0.016 \\
\hline RWS 2 & 0.101 & 0.0010 & 12.4 & 0.347 & 2.43 & 0.028 \\
\hline
\end{tabular}

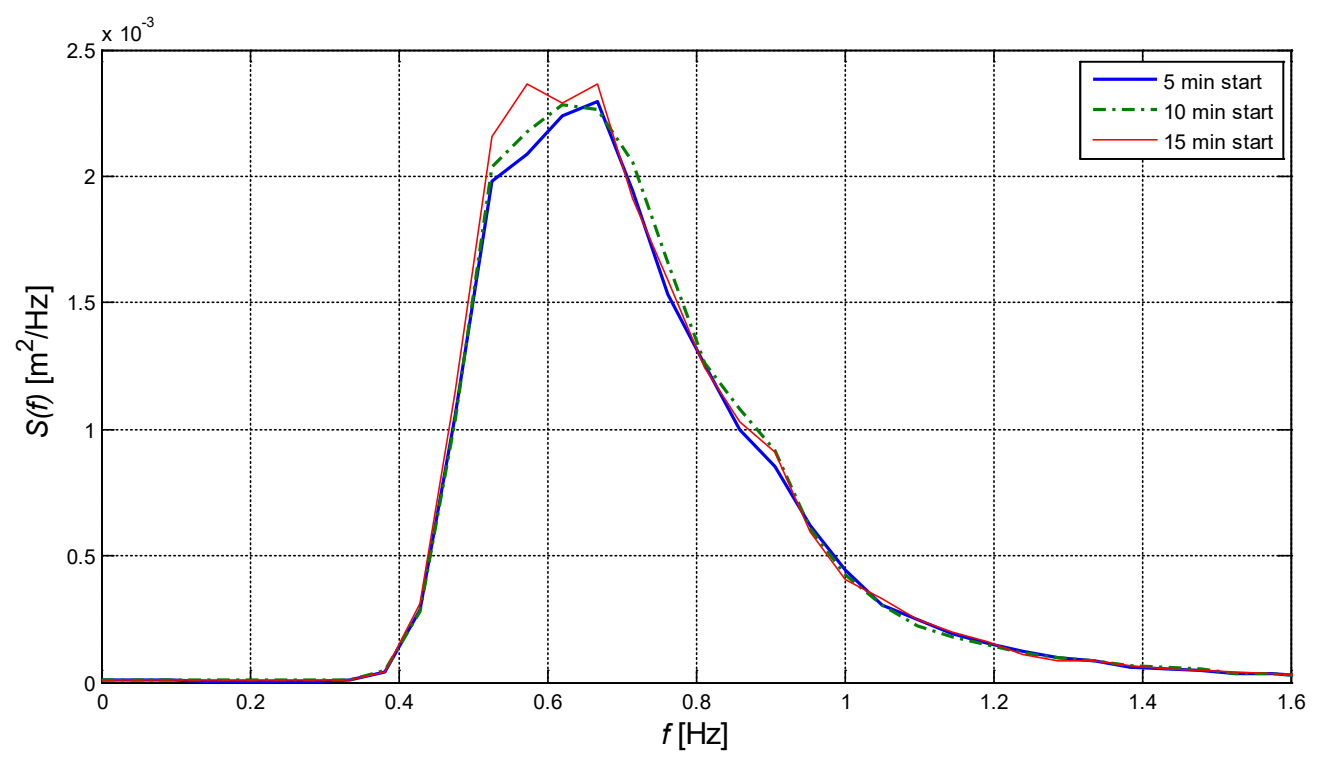

Figure 8. Wave spectra for the IWS 1 for the three 25-minute window data sets with start times staggered by 5 minutes 


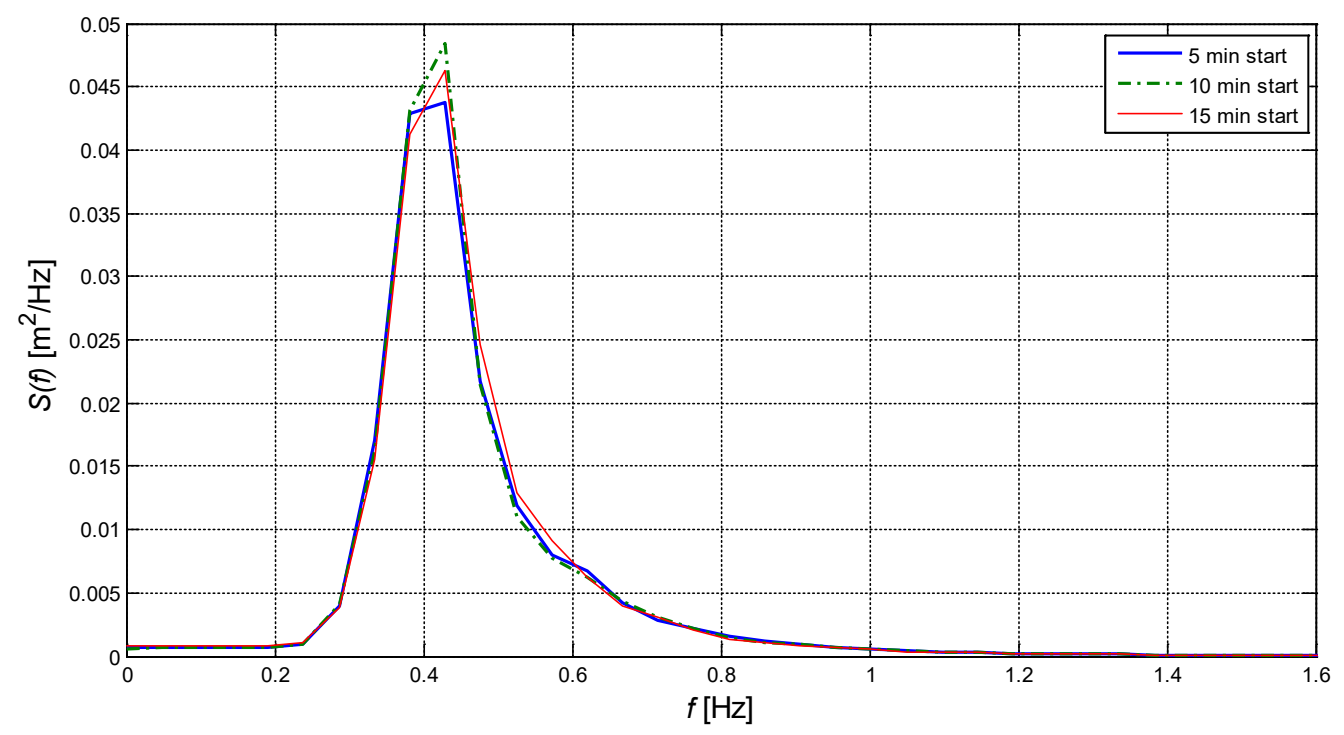

Figure 9. Wave spectra for the LIWS 2 for the three 25-minute window data sets with start times staggered by 5 minutes

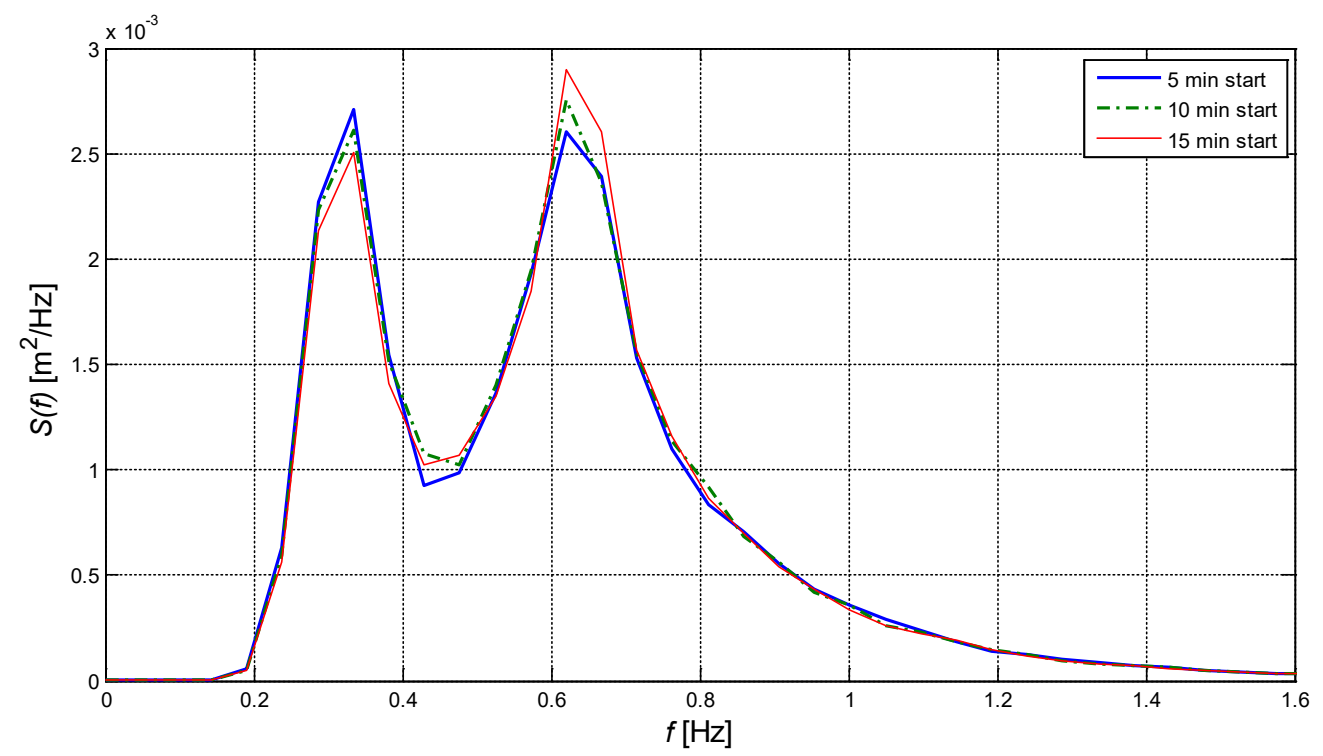

Figure 10. Wave spectra for the RWS 1 for the three 25-minute window data sets with start times staggered by 5 minutes

\subsection{Data Acquisition, Sensors, Data Quality Assurance}

Prize measurements consisted of wave height, mooring loads, PTO variables, and device motion. The wave measurements were provided by sets of acoustic and capacitive wave sensors located upstream of the WEC test station at $0 \mathrm{deg}$ and $-70 \mathrm{deg}$. A National Instruments Compact RIO (primary cRIO) data acquisition system was used to sample the PTO and mooring load sensor at $100 \mathrm{~Hz}$. A natural point tracking system was used to track the motion of each body in the WECs at $100 \mathrm{~Hz}$. The wave probes were on separate cRIO systems. The primary cRIO interfaced with the natural point tracking system and the wave data acquisition system to ensure tight data synchronization. Data streams were fed from the primary cRIO to the team if they needed the 
data to support their control. The prize judges recommended that each team have sensors with a National Institute of Standards and Technology (or equivalent) traceable calibration. For sensors without National Institute of Standards and Technology traceable calibration, the prize judges asked the team to have third-party calibrations performed to ensure sensor accuracy. During the first week of testing, the prize judges performed spot checks on every team-provided sensor to ensure calibration certificate validity and third-party calibrations were accurate.

Given that each team had only one week in the basin to deploy, test, and recover, and because the test schedule was tight, it was critical to ensure that all sensors were performing properly and to identify and fix any issues as they occurred instead of waiting for post-processing. This methodology allowed issues to be addressed as they were identified so tests could be repeated as needed; thus, each team had the best possible opportunity to complete all test runs with a full suite of working sensors.

Data were recorded on the Carderock data acquisition system for each test; then, at the end of the run, data were recorded to an optical disc and given to the data analysist. The Carderock data acquisition system was able to display time series of all individual channels and the calculated power, in engineering units, in real time. Between each run, the data analysist processed the data and performed a quality assurance review. The quality assurance consisted of several checks:

a. All channels were automatically checked to identify NaNs, repeated values, and empty data streams;

b. The time stamp was reviewed to ensure measurement continuity and that the data acquisition system did not freeze or skip measurements;

c. Wave time series were reviewed against threshold values and wave statistics $\left(\overline{H_{S}}\right.$ $\bar{J}$, and $T_{E}$ ), and spectra were compared with the theoretical and baseline (calibration) spectra;

d. Kinematic, dynamic, and calculated power time series were reviewed against threshold values for all PTOs;

e. Mooring load time series were reviewed against threshold values for mooring loads, and peak values were identified for the $H P Q$ calculation;

f. Time series of PTO travel were reviewed against end stop thresholds, and peak values were identified for the $H P Q$ calculation; and

g. The time horizontal motions of the primary body were reviewed and peak values were identified for the $H P Q$ calculation.

Prior to proceeding to the next test, results were reviewed by the team, the prize test lead, the data analyst, and a prize administrator. 


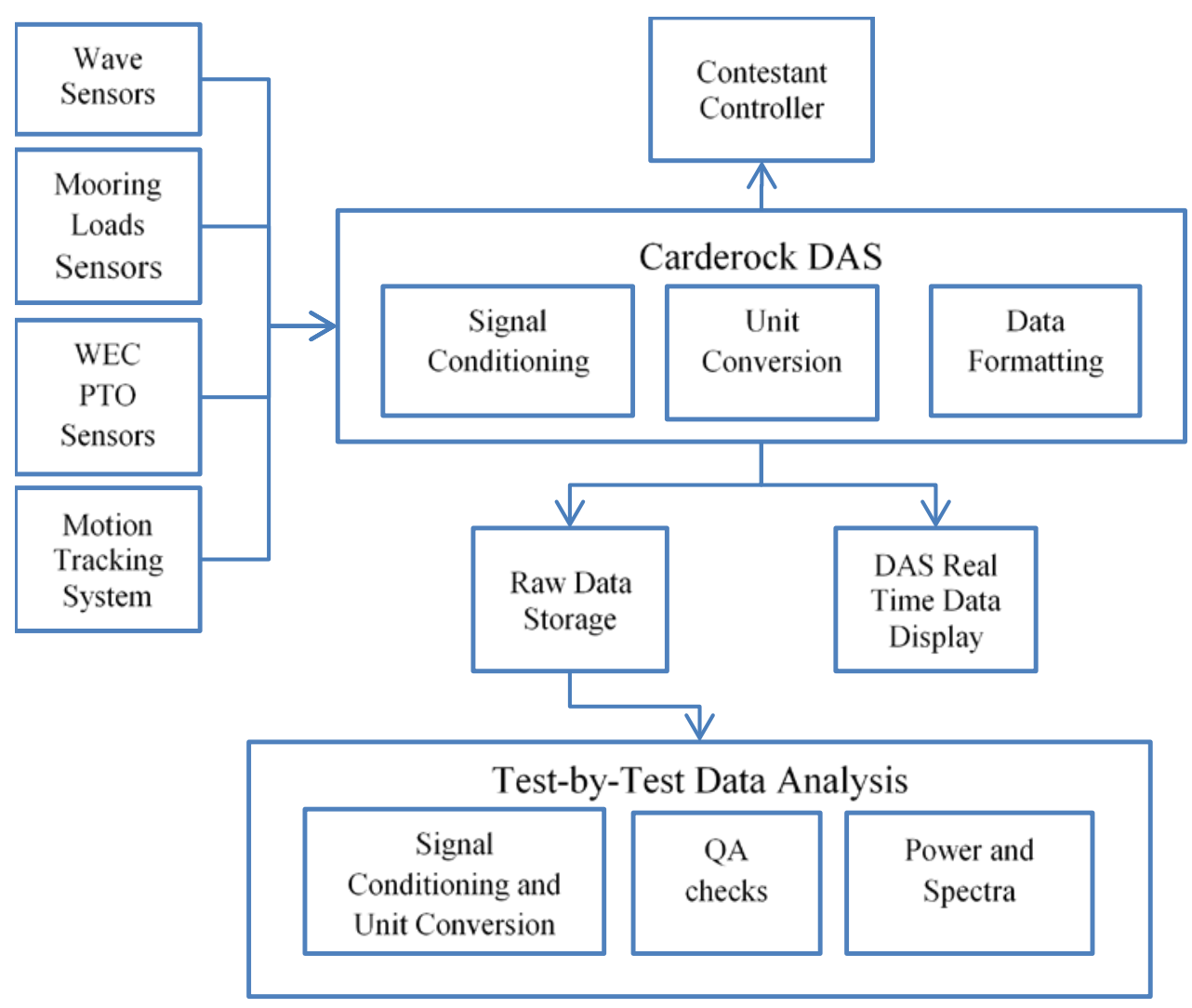

Figure 11. Schematic showing the data flow from the sensors through the data acquisition system (DAS) and to the processing and quality assurance that was provided between tests 


\section{Conclusions}

The DOE's Wave Energy Prize contest made a lasting contribution to the development of an ocean wave energy conversion industry, not only from stimulation of team contestant and finalist technical progress, but also in terms of the technology evaluation methodologies. The $A C E$ metric represents an advancement in the comparative evaluation of low TRL WECs because it accounts for structural costs in an equitable manner. The $A C E$ was fundamentally developed as a ratio of the energy absorption performance via $A C C W$ - determined via 1:20 scale tank testingto the estimated structural cost via $C C E$ determined using a structural analysis of the key structures and estimates of the $M M C$. To account for other contributors to the LCOE, the resulting $A C E$ value was modified by a performance-based scale factor called hydrodynamic performance quality $(H P Q)$, determined from other data collected during testing and summarized in this report. It is hoped that the $A C E$ and $H P Q$ metrics will see further development and use in the techno-economic evaluation of low TRL technologies in the future.

While the $A C E$ metric satisfies its purpose as a proxy for LCOE for low TRL technologies in the Wave Energy Prize, it has limitations that can be improved to increase its utility. For example, $A C E$ could capture PTO and balance of station costs at levels of detail appropriate for low TRLs. Guidelines could also be developed for the level of information and the fidelity of that information needed for different TRLs, up until a full LCOE calculation is possible. 


\section{References}

[1] DOE, "Technology Readiness Assessment Guide, DOE G 413.3-4A," U.S. Department of Energy, Washington D.C., 2011.

[2] J. Weber, "WEC Technology Readiness and Performance Matrix - Finding the Best Research Technology Development Trajectory," in International Conference on Ocean Energy, Dublin, Ireland, 2012.

[3] DOE, "Wave Energy Prize Rules 4.25.16 R3," 2016. [Online]. Available: https://waveenergyprize.org/downloads/Wave_Energy_Prize_Rules_4_25_16_R3.pdf. [Accessed 27 June 2017].

[4] A. LaBonte, P. O'Connor, C. Fitzpatrick, K. Hallet and Y. Li, "Standardized Cost and Performance Reporting for Marine and Hydrokinetic Technologies," in Marine Energy Technology Symposium, Washington, D.C., 2013.

[5] A. Babarit, "A Database of Capture Width Ratio of Wave Energy Converters," Renewable Energy, vol. 80, no. 2015, pp. 610-628, 2015.

[6] V. Neary, M. Previsic, R. L. M. Jepsen, Y. Yu, A. Copping, A. Fontaine, K. Hallet and D. Murray, "Methodology for Design and Economic Analysis of Marine Energy Conversion (MEC) Technologies," Sandia National Laboratories , Albuquerque, NM, 2014.

[7] A. De Andres, J. Maillet, J. Hals, P. Moller, D. Bould and H. Jeffrey, "Techno-Economic Related Metrics for a Wave Energy Converters Feasibility Assessment," Sustainability, vol. 8, 2016.

[8] SI Ocean, "Cost of Energy and Cost Reduction Opportunities," Strategic Initiative for Ocean Energy, 2013.

[9] J. Falnes, "A resonant point absorber of ocean-wave power.," Nature, vol. 256, pp. 478-9, 1975.

[10] R. Blevins, Applied Fluid Dynamics Handbook, Van Nostrand Reinhold Company Inc., 1984.

[11] C. Trust, "Cost Estimating Methodology.," Commissioned by the Carbon Trust and carried out by Entec UK Ltd., 2006.

[12] IEA-OES, "International Levelized Cost of Energy for Ocean Energy Technologies," IEAOES, 2015.

[13] J. D, Y. Yu and V. Neary, "Levelized Cost of Energy Analysis of Marine and Hydrokinetic Reference Models," in Marine Energy Technology Symposium, Washington, D.C. , 2015.

[14] D. Bull and A. Dallman, "Wave Energy Prize Experimental Sea State Selection for the Benefit-to-Effort Threshold Metric, ACE," in 5th Marine Energy Technology Symposium, Washington, D.C. , 2017.

[15] J. Mandell, D. M. D. Samborsky, P. S. A. Agastra, J. Paquette, Naughton and B, "Analysis of SNL/MSU/DOE Fatigue Database Trends for Wind Turbine Blade Materials, 20102015," Sandia National Laboratories, Albuquerque, New Mexico and Livermore, California, 2016.

[16] T. Composites, "Cost Study for Large Wind Turbine Blades: WindPACT Blade System Design Studies," Sandia National Laboratories, Albuquerque, NM, 2003. 
[17] G. Saur, B. Maples, M. Meadows, M. Hand and W. Musial, "Offshore Wind Plant Balance of Station Cost Drivers and Sensitivities," National Renewable Energy Laboratory, Golden, CO, 2012.

[18] M. Previsic, "Cost Breakdown Structure for WEC Rated at 286kW," 2012. [Online]. Available: http://energy.sandia.gov/download/23667/. [Accessed 29 June 2017].

[19] S. Jenne, "RM5 Component Cost and LCOE Calculations Spreadsheet," 20142014. [Online]. Available: http://energy.sandia.gov/download/23713/. [Accessed 29 June 2017].

[20] S. Jenne, "Cost Breakdown Structure for RM6 Based off of RM3 Layout," 2014. [Online]. Available: http://energy.sandia.gov/download/23739/. [Accessed 29 June 2017].

[21] L. Fingersh, M. Hand and A. Laxson, "Wind Turbine Design Cost and Scaling Model," National Renewable Energy Laboratory, Golden, CO, 2006.

[22] Directional Wave Spectra Using Cosine-squared and Cosine 2S Spreading Functions, U.S. Army Engineer Waterways Experiment Station, Coastal Engineering Research Center, 1985.

[23] R. Dean and R. Dalrymple, Water Wave Mechanics for Engineers and Scientists, World Scientific, 1992.

[24] API, "API Bull 2V: Design of Flat Plate Structures," American Petroleum Institute, 2004.

[25] Y. Yu, D. T. R. C. A. Jenne, S. Geerlofs and L. Hanna, "Reference Model 5 (RM5): Oscillating Surge Wave Energy Converter," National Renewable Energy Laboratory, Golden, CO, 2015. 


\section{Appendix A - RST and MMC Examples}

The DOE RM3 (point absorber) was determined through detailed structural analysis to have an average thickness of approximately $3.3 \mathrm{~cm}$. The total simplified surface area of the RM3 geometry is approximately $2,623 \mathrm{~m}^{2}$, resulting in a volume of approximately $8,662 \mathrm{~m}^{3}$. Given that the RM3 structure uses A36 steel with a density of $7,850 \mathrm{~kg} / \mathrm{m}^{3}$, one can estimate the device mass to be approximately $680,000 \mathrm{~kg}$ or 680 tonnes. The typical $M M C$ value used for fabricated steel devices in the prize was $\$ 3,000 /$ tonne, translating to a $C C E$ of $\$ 2.04 \mathrm{M}$. This is slightly higher than the actual structural cost of RM3 due to an increased $M M C$ value; however, this is representative of the baseline $A C E$ value. This $C C E$ example is shown in the following table and equations:

\begin{tabular}{|l|l|}
\hline Parameter & Value \\
\hline Material & Steel \\
\hline Density & $7,850 \mathrm{~kg} / \mathrm{m}^{3}$ \\
\hline$R S T$ & $3.3 \mathrm{~cm}$ \\
\hline Simplified Surface Area & $2,623 \mathrm{~m}^{2}$ \\
\hline$M M C$ & $\$ 3,000 /$ tonne \\
\hline
\end{tabular}

$$
\begin{gathered}
C C E=\sum_{k=1}^{L} \rho_{k} \cdot A_{k} \cdot R S T_{k} \cdot M M C_{k} \\
\$ 2.04 M=\left(7,850 \frac{\mathrm{kg}}{\mathrm{m}^{3}}\right) \cdot\left(2,623 \mathrm{~m}^{2}\right) \cdot(3.3 \mathrm{~cm})\left(3,000 \frac{U S D}{\text { tonne }}\right)
\end{gathered}
$$

In many design scenarios, calculating the $R S T$ is redundant and can be skipped if an appropriate structural design is used to approximate the total device mass. For example, in the case of the Reference Models, structural mass was determined through iterative design using finite element analysis. Once an allowable stress level was obtained, the mass was then calculated from the specific computer-assisted design model. However, in the instance of early-stage hydrodynamic designs where only a simplified geometry is known, assuming an $R S T$ can be useful to quickly estimate the $C C E$ and/or $A C E$ value. 


\section{Appendix B - Example Structural Analysis}

Each structural component has been evaluated using simplified structural models that predict the material mass for a given geometry. Each structural model assumes a wave load, either hydrostatic or hydrodynamic or both, as well as resistive loads where applicable (i.e., generator torque). An example for a component that is primarily driven by hydrodynamic loading is the circular float in the simplified RM3 geometry as shown in Figure 12. Using linear wave theory, one can approximate the pressure load acting on a body given a wave height and wave period [23]. In the simplified models, this load is applied to a given area. In the case of RM3 that area is the bottom of the cylindrical float. The cylindrical float is discretized, similar to how the device would likely be manufactured. The cylindrical annulus is simplified into rectangular flat plate sections, allowing for both a beam and plate analysis. This simplification is represented as the shaded blue box in Figure 13.
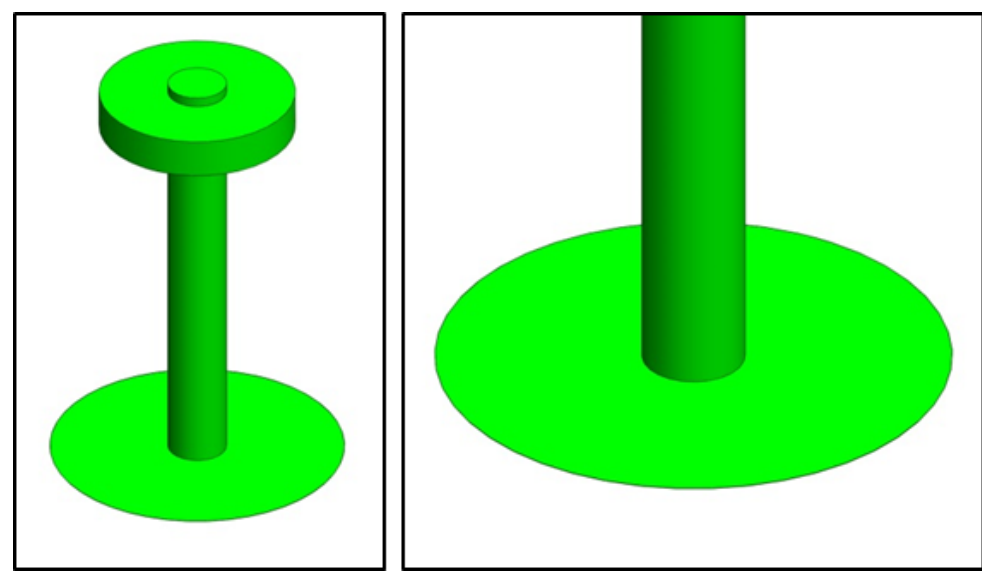

Figure 12. Simplified RM3 Geometry

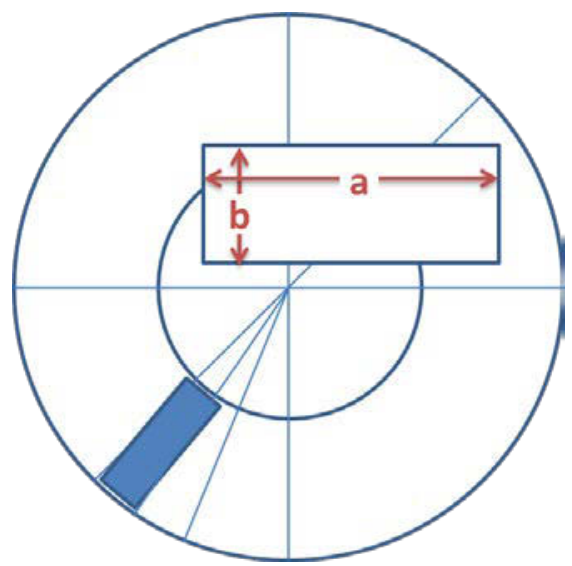

Figure 13. Simplified discretization of circular cross section

The model is then able to solve for a series of standard beams (T-stiffeners, I-beam, etc.) and a required plate thickness. Each model has a lookup table that selects a beam based on the minimum weight for a given failure criterion. The failure criterion selected was the allowable stress, which is determined by the material yield stress and a predetermined safety factor. The 
safety factor assigned was selected through a combination of the allowable stress used for other offshore designs [24] and calibrating the models to actual RM3 RST values. This led to the design safety factor of 1.75 , equivalent to a material load factor of approximately 0.57 .

Additional failure criteria could have been selected, such as deflection, but for consistency material stress was the only criterion used. This stress calculation is then run for a given number of beams, defined and iterated by the user, to determine which stiffeners meet the failure criterion. Of the beams that have an acceptable allowable stress, the lightest beam is selected for the structural design. Similar calculations are used for columns in buckling in the $\mathrm{z}$ direction. Once the internal beam structure has been defined, the model then calculates the required outer plate thickness for the area defined by "a" and "b" in Figure 13. The mass of the component(s) is then summed for all the components and divided by the outer surface area and material density to determine the $R S T$.

For composite structures, the methodology is the same as described above but with one variation. Instead of using the material yield stress, a strain-derived stress is used to account for failures seen in large-thickness composite structures [15]. Using the relationship between stress and strain, the Young's Modulus is used to calculate an allowable stress, given a strain-driven failure criterion. As shown by Mandell et al. the allowable failure in large composite parts happens near a tensile strain of $3 \%$ (or $3,000 \mu \varepsilon$ ) [15]. The following is an example of how to calculate the adjusted yield stress for a composite material.

Using:

where:

$$
E_{\text {material }}=\frac{\sigma_{\text {tensile }}}{\varepsilon_{\text {tensile }}}
$$

$$
\begin{aligned}
& E_{\text {E-Glass/Epoxy }}=10,600 \mathrm{MPa} \\
& \varepsilon_{\text {Allowable }}=0.003 \mathrm{~m} / \mathrm{m} \\
& F O S=1.75 \\
& \sigma_{\text {Allowable }}=\left(10,600 \mathrm{MPa} * 1,000 \frac{\mathrm{kPa}}{\mathrm{MPa}}\right) *\left(\frac{.003}{1.75}\right)=18,171 \mathrm{kPa}
\end{aligned}
$$

For comparison, small-scale coupon tests suggest that for a material of this layup, the yield stress is on the magnitude of $344,000 \mathrm{kPa}$. Therefore, if we remove the factor of safety of 1.75 , the reader can see that the strain-driven stress value is roughly an order of magnitude smaller. 


\section{Appendix C - Wave Repeatability and Spatial Variability Analysis}

A comparison of wave measurements for four random teams using the capacitive wave probes located $17 \mathrm{~m}$ ahead of the WEC test area is shown in Figures 14 through 17. The correlation coefficient between the wave time series measured for the four different teams was typically greater than 0.9 . The spectra for all four teams were in very close agreements. The WECs were in the water and operating, thus any discrepancy is likely due to the WECs influence on the wave field and measurement error.
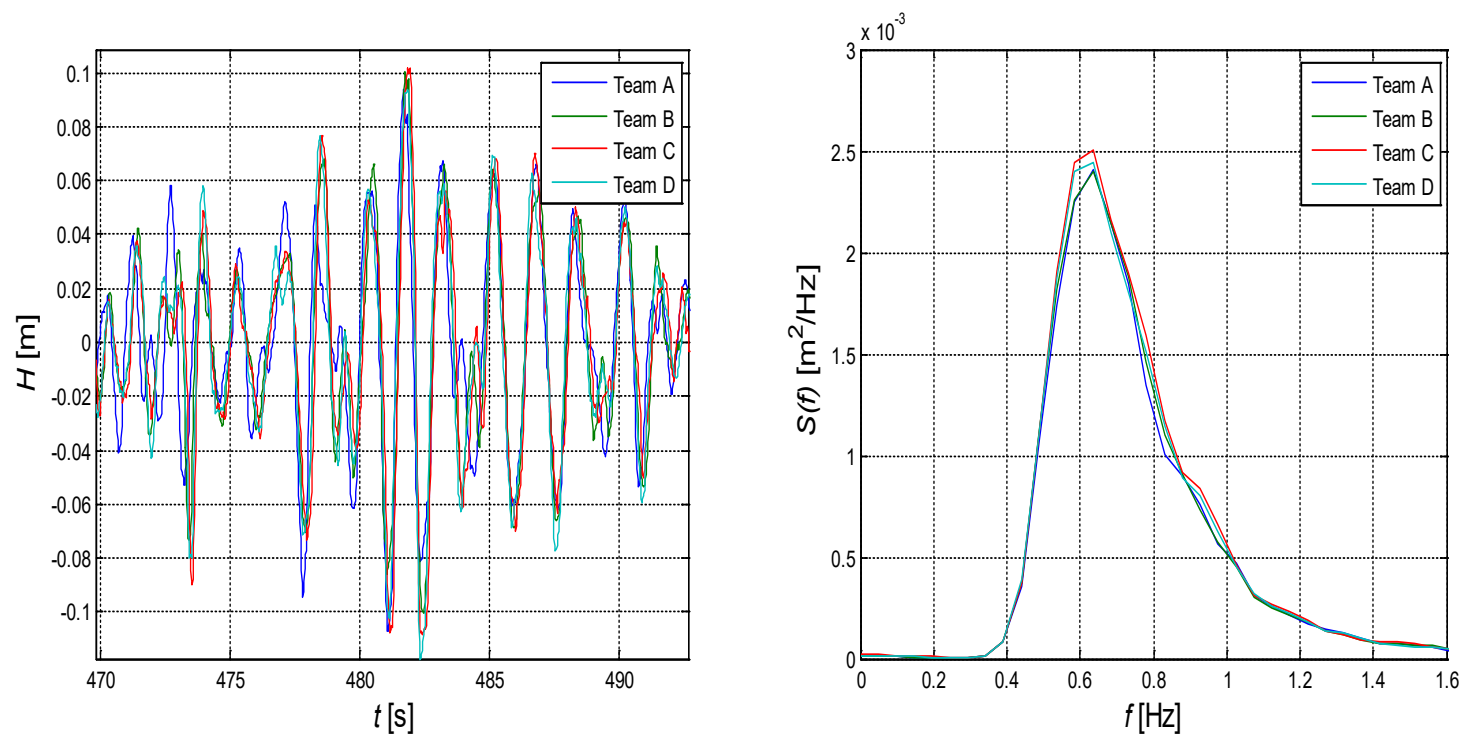

Figure 14. Time series of the same IWS 1 wave for four different teams (left figure) and spectra of the same IWS 1 wave for four different teams (right figure)
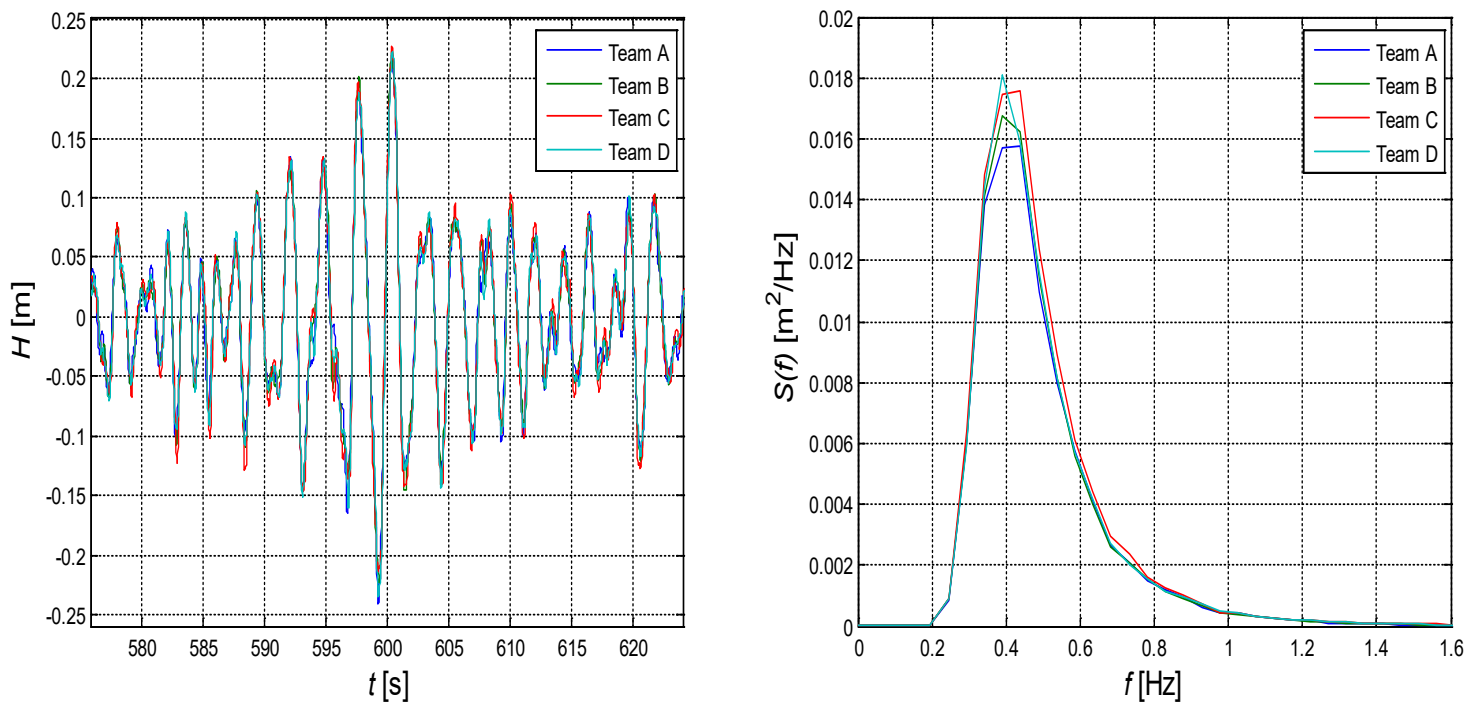

Figure 15. Time series of the same IWS 3 wave for four different teams (left figure) and spectra of the same IWS 3 wave for four different teams (right figure) 

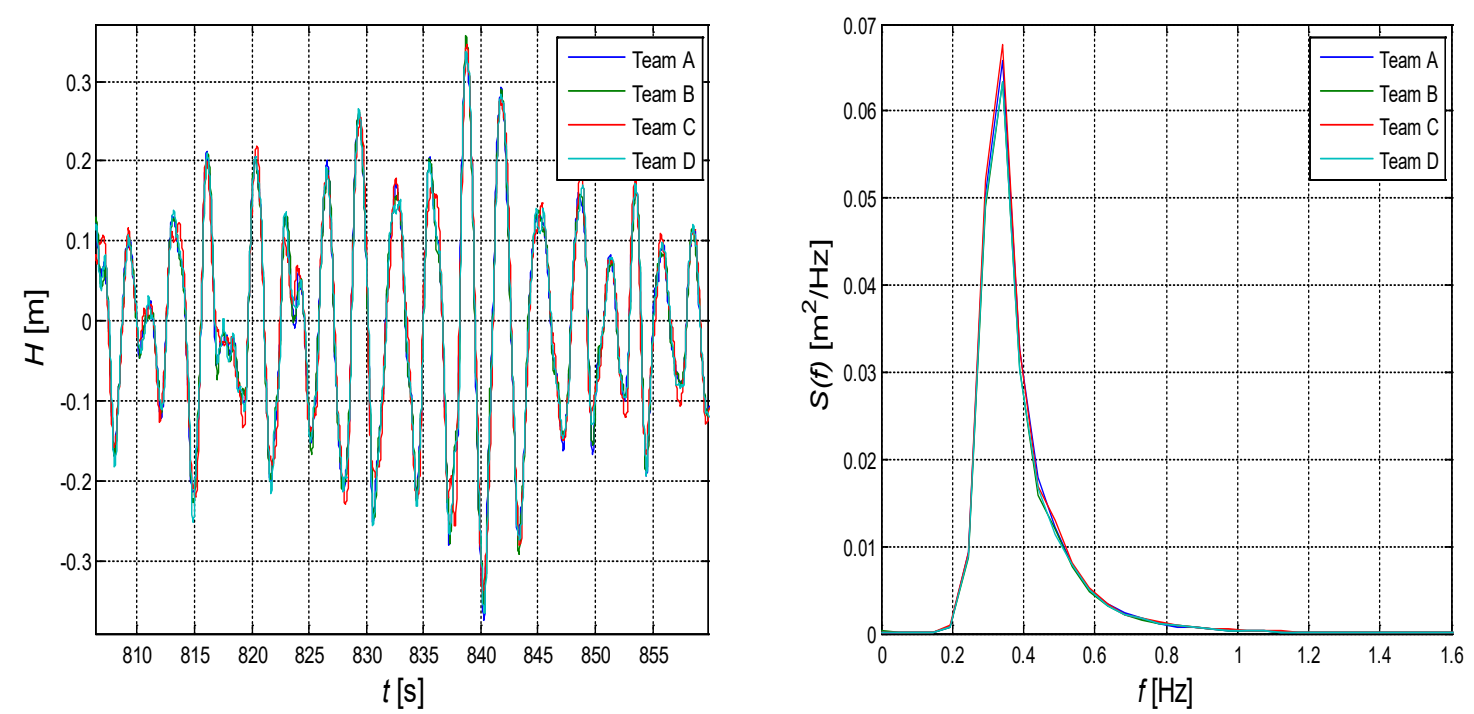

Figure 16. Time series of the same LIWS 1 wave for four different teams (left figure) and spectra of the same LIWS 1 wave for four different teams (right figure)
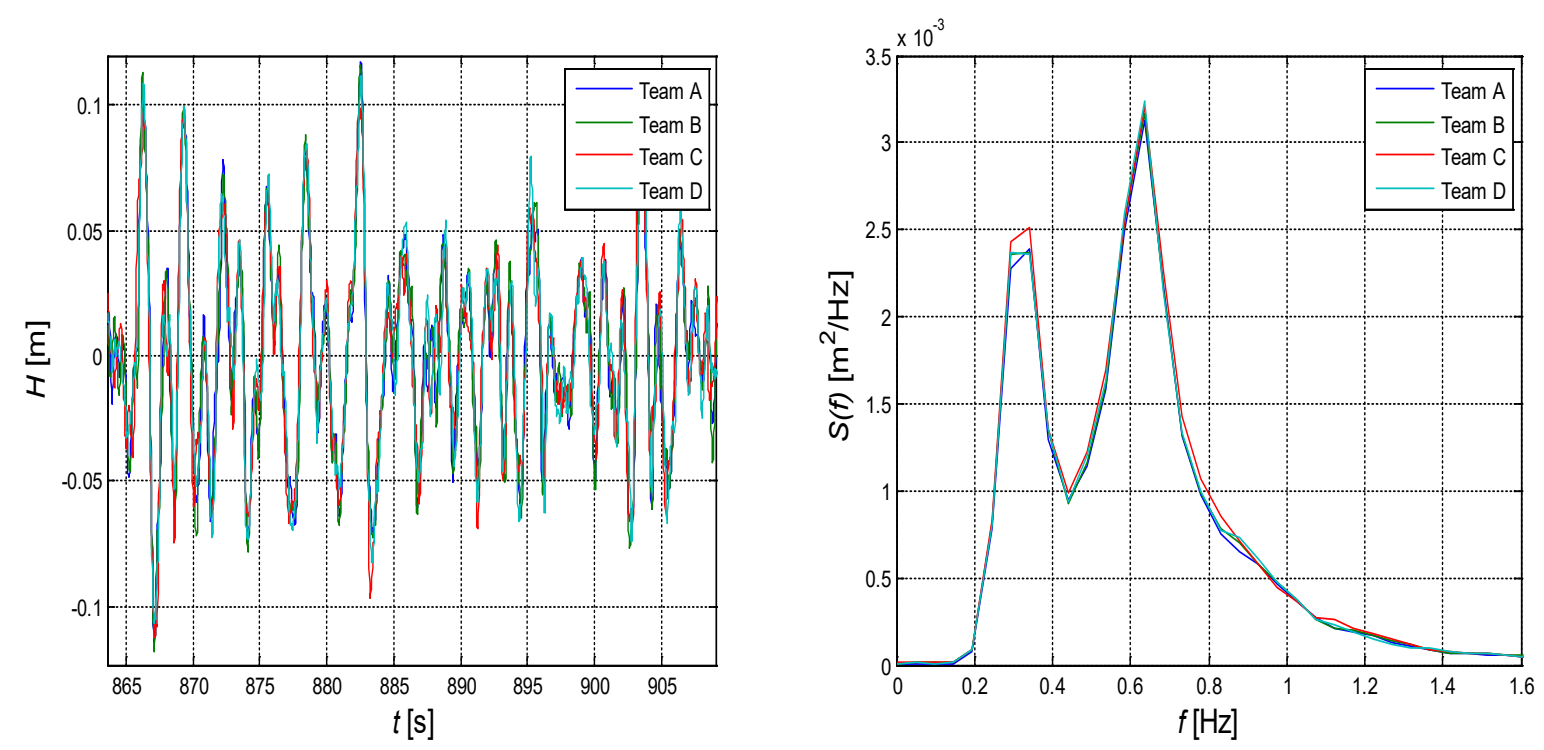

Figure 17. Time series of the same RWS 1 wave for four different teams (left figure) and spectra of the same RWS 1 wave for four different teams (right figure)

To quantify the spatial variability of the wave field within the test area, for each of the ten test sea states, the spectra for each of the 12 wave probes were calculated. The spectra from the 12 wave probes and the average spectra, along with the specified spectra, are shown for four of the 10 sea states in Figures 18 through 21- one small, one medium, one storm, and one multidirectional sea state. 

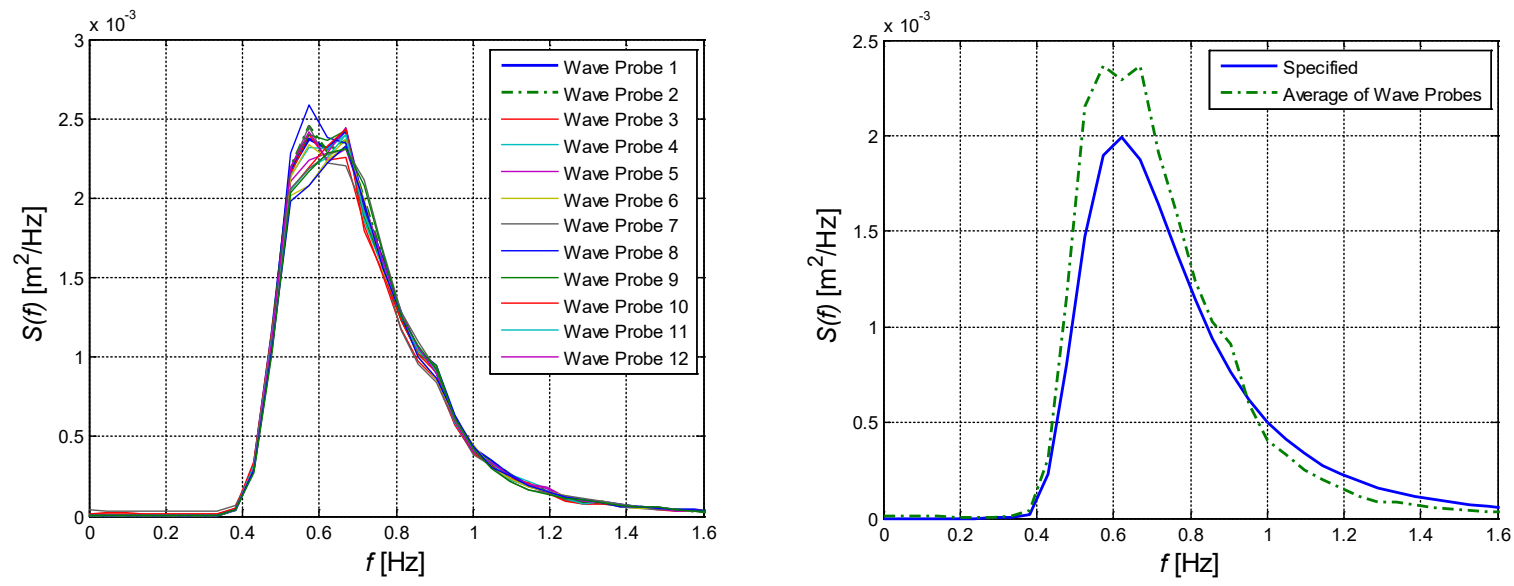

Figure 18. Spectra for all 12 calibration wave probes for IWS 1 (left) and the average spectra for all 12 calibration wave probes and the specified JONSWAP for IWS 1 (right)
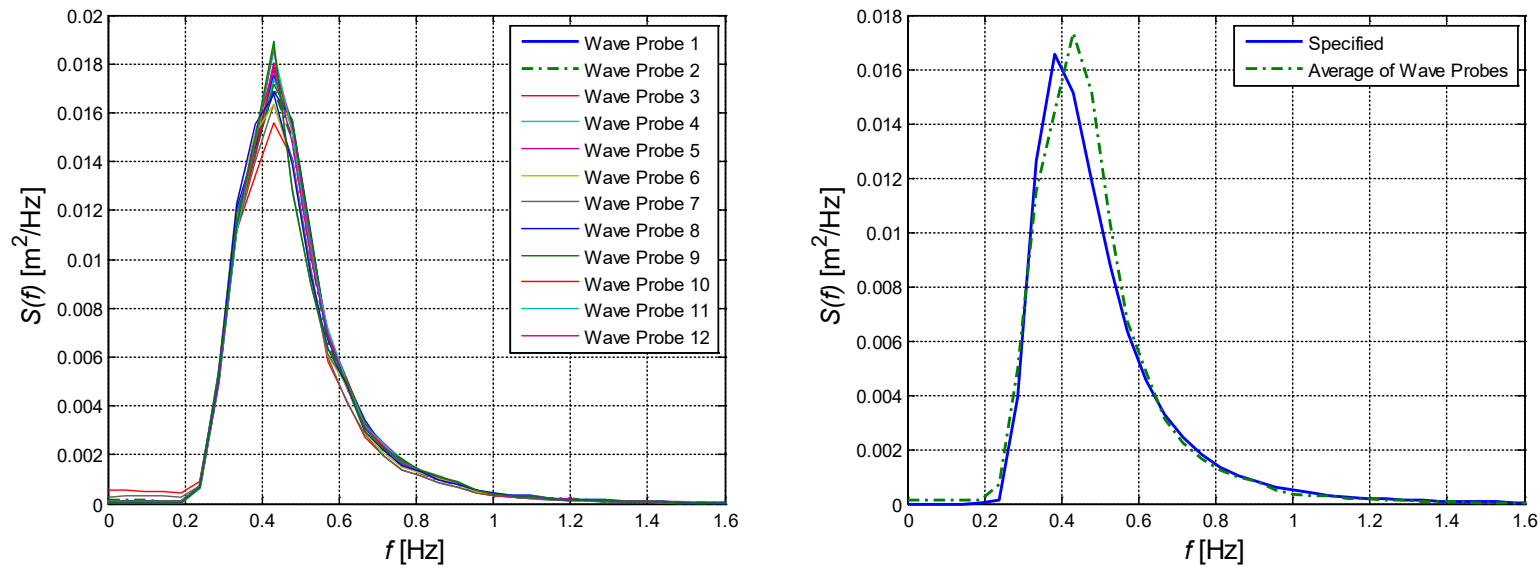

Figure 19. Spectra for all 12 calibration wave probes for IWS 3 (left) and the average spectra for all 12 calibration wave probes and the specified JONSWAP for IWS 3 (right)
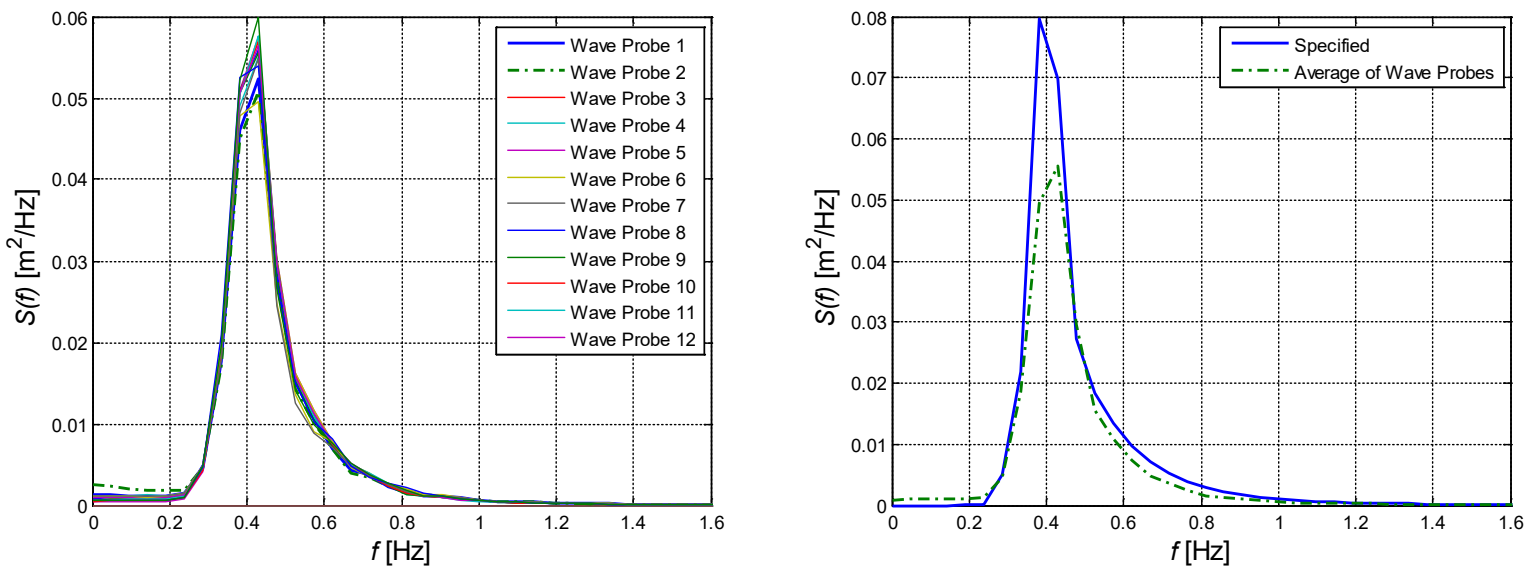

Figure 20. Spectra for all 12 calibration wave probes for LIWS 2 (left) and the average spectra for all 12 calibration wave probes and the specified JONSWAP for LIWS 2 (right) 

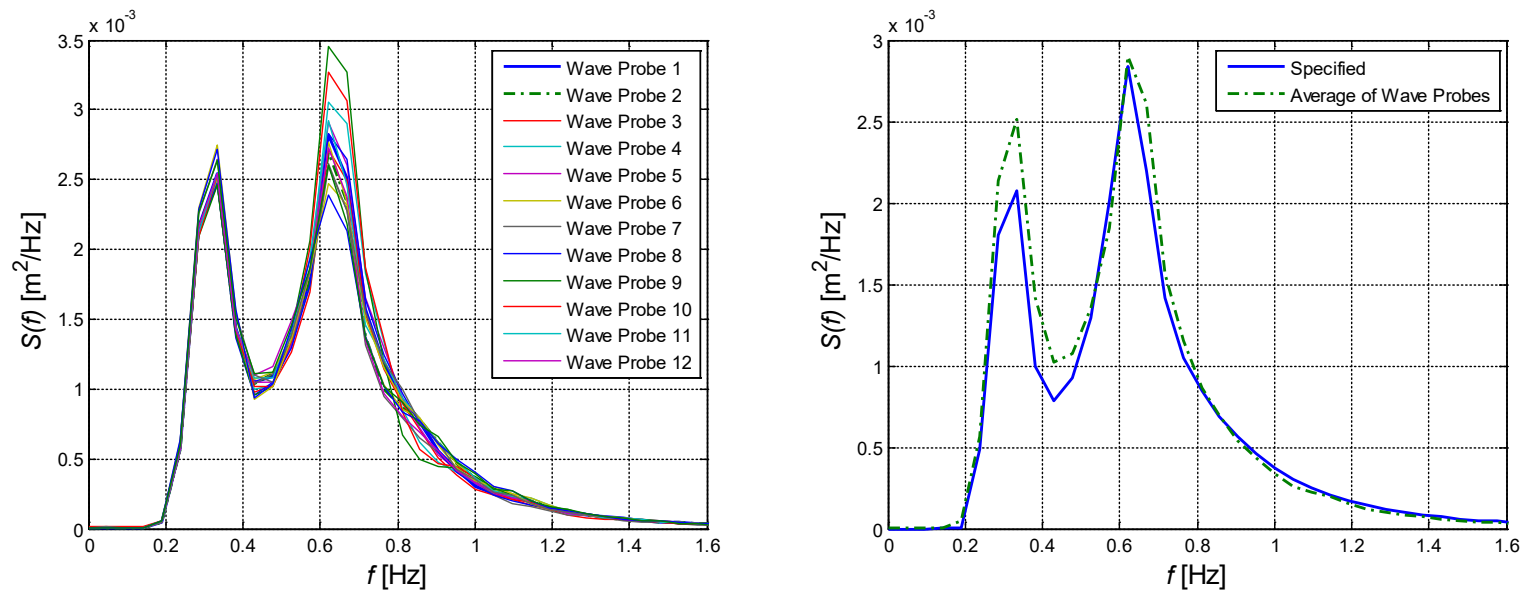

Figure 21. Spectra for all 12 calibration wave probes for RWS 1 (left) and the average spectra for all 12 calibration wave probes and the specified JONSWAP for RWS 1 (right) 